\title{
Global Wildland Fire Emission Model (GWEM): Evaluating the use of global area burnt satellite data
}

\author{
Judith J. Hoelzemann, Martin G. Schultz, Guy P. Brasseur, and Claire Granier ${ }^{1,2}$ \\ Max Planck Institute for Meteorology, Hamburg, Germany \\ Muriel Simon \\ European Space Agency (ESA) ESRIN, Frascati, Italy \\ Received 5 April 2003; revised 21 January 2004; accepted 16 February 2004; published 5 June 2004.
}

[1] The new Global Wildland Fire Emission Model (GWEM) has been developed on the basis of data from the European Space Agency's monthly Global Burnt Scar satellite product (GLOBSCAR) and results from the Lund-Potsdam-Jena Dynamic Global Vegetation Model (LPJ-DGVM). GWEM computes monthly emissions of more than 40 chemical compounds and aerosols from forest and savanna fires. This study focuses on an evaluation of the GLOBSCAR data set. The GWEM version presented here makes use of the Moderate-Resolution Imaging Spectroradiometer (MODIS) land cover map. Emission totals for the year 2000 are $1741 \mathrm{Tg} \mathrm{C}, 5716 \mathrm{Tg} \mathrm{CO}_{2}, 271 \mathrm{Tg} \mathrm{CO}, 12.52 \mathrm{Tg} \mathrm{CH}_{4}$, 9.09 $\mathrm{Tg} \mathrm{C}$ (as nonmethane hydrocarbons), 8.08 $\mathrm{Tg} \mathrm{NO}_{\mathrm{x}}$ (as $\mathrm{NO}$ ), 24.30 $\mathrm{Tg} \mathrm{PM}_{2.5}$, 15.80 Tg OC, and 1.84 Tg black carbon. These emissions are lower than other estimates found in literature. An evaluation assesses the uncertainties of the individual input data. The GLOBSCAR product yields reasonable estimates of burnt area for large wildland fires in most parts of the globe but experiences problems in some regions where small fires dominate. The seasonality derived from GLOBSCAR differs from other satellite products detecting active fires owing to the different algorithms applied. Application of the presented GWEM results in global chemistry transport modeling will require additional treatment of small deforestation fires in the tropical rain forest regions and small savanna fires, mainly in subequatorial Africa. Further improvements are expected from a more detailed description of the carbon pools and the inclusion of anthropogenic disturbances in the LPJ model. INDEX TERMS: 0315 Atmospheric Composition and Structure: Biosphere/atmosphere interactions; 0368 Atmospheric Composition and Structure:

Troposphere - constituent transport and chemistry; 0322 Atmospheric Composition and Structure: Constituent sources and sinks; 1615 Global Change: Biogeochemical processes (4805); KEYWORDS: vegetation fire emissions, global area burnt satellite products, tropospheric chemistry

Citation: Hoelzemann, J. J., M. G. Schultz, G. P. Brasseur, C. Granier, and M. Simon (2004), Global Wildland Fire Emission Model (GWEM): Evaluating the use of global area burnt satellite data, J. Geophys. Res., 109, D14S04, doi:10.1029/2003JD003666.

\section{Introduction}

[2] Global wildland fires yield an important contribution to the chemical budget of the troposphere [e.g., Seiler and Crutzen, 1980]. For the scope of this paper the term wildland fire denotes all savanna and forest fires, even those ignited by human activity. This includes fires for land clearing, pest control, or fertilization. During a wildland fire, chemical compounds of the burning vegetation are released and in some ecosystems injected into considerable altitudes of several kilometers [Lavoué, 2000; Liousse et al., 1996], where they can be transported over long-range

\footnotetext{
${ }^{1}$ Also at Service d'Aeronomie, University of Paris VI, Paris, France.

${ }^{2}$ Also at Cooperative Institute for Research in Environmental Sciences/ NOAA Aeronomy Laboratory, Boulder, Colorado, USA.

Copyright 2004 by the American Geophysical Union. 0148-0227/04/2003JD003666\$09.00
}

distances [Andreae et al., 2001; Stohl et al., 2002]. During these transport processes, several of the chemical gases or particles are transformed by heterogeneous- and gasphase chemistry as well as by aerosol microphysics and thermodynamics.

[3] The dominant fraction of the emissions contains carbon. Most of the carbon (about 90\%) is emitted in the form of carbon dioxide $\left(\mathrm{CO}_{2}\right)$ or carbon monoxide $(\mathrm{CO})$. Most of he remaining carbon splits into emission of methane $\left(\mathrm{CH}_{4}\right)$, nonmethane hydrocarbons (NMHC), and oxygenated volatile organic compounds (O VOC) [Andreae and Merlet, 2001]. Less than $5 \%$ of the carbon is released as particulate matter (J. S. Reid, manuscript in preparation, 2003). Other important species released are nitrogen oxides $\left(\mathrm{NO}_{\mathrm{x}}=\mathrm{NO}+\mathrm{NO}_{2}\right)$.

[4] The effects of wildland fire emissions are diverse and significant: the contribution to the annual gross global $\mathrm{CO}$ budget, for example, is about $40 \%$ [Intergovernmental 
Panel on Climate Change (IPCC), 2001]. $\mathrm{CO}$ and $\mathrm{NO}_{\mathrm{x}}$ are important precursors for ozone. Elevated ozone concentrations are often observed in considerable distance of fire sources [Fishman et al., 1996]. The aerosols released from wildland fires comprise mainly organic carbonaceous compounds (OC), black carbon (BC), and trace inorganic species such as potassium, chlorine, and calcium (J. S. Reid, manuscript in preparation, 2003). The emitted particles alter solar and terrestrial radiation by scattering and absorption [IPCC, 2001] and can therefore have an effect on global warming [Twomey, 1977]. Furthermore, they can act as cloud condensation nuclei [Twomey and Warner, 1967; Hobbs and Radke, 1969] and might therefore modify precipitation patterns.

[5] Wildland fires, along with agricultural waste burning and domestic fuel use (subsumed under the term biomass burning), have gained the attention of the atmospheric chemistry modeling community since the 1980s [Seiler and Crutzen, 1980]. When the first chemistry transport models (CTMs) were developed, it was recognized that emissions from wildland fires should be included to realistically represent the distribution of ozone and its precursors. Similarly, realistic aerosol simulations are not possible without taking the burning of vegetation into account.

[6] One of the first approaches for a global wildland fire emission inventory was performed by Hao et al. [1990] followed by Hao and Liu [1994], Cooke and Wilson [1996], Galanter et al. [2000], Lobert et al. [1999], and Lavoué et $a l$. [2000]. These inventories typically represent climatological annual totals of wildland fire emissions [Hao and Liu, 1994; Galanter et al., 2000]. Recently, the considerable interannual variability of fire emissions has been investigated by, e.g., Duncan et al. [2003], Schultz [2002], Generoso et al. [2003], Wotawa et al. [2001], and Hély et al. [2003a].

[7] However, the abovementioned inventories rely on incomplete and scattered input data. Errors are usually assumed to be very large and data are of inconsistent quality on the global scale. For many regions, data from groundbased or airborne surveys are not available and where available, they are often inconsistent, inaccurate, or lack the necessary temporal resolution (at least monthly) to capture the highly variable wildland fire emission behavior.

[8] A number of recent studies apply satellite data to improve the existing climatological emission inventories. Emissions are scaled to global active fire count data from satellites such as the Along-Track Scanning Radiometer (ATSR-2) of the European Space Agency (ESA) [Arino et al., 2001; Arino and Plummer, 2001]. Duncan et al. [2003] determined an average seasonal variation of biomass burning out of four years of ATSR fire count data (1996-2000) on the basis of the emission inventory by Yevich and Logan [Lobert et al., 1999] and derived the interannual variability of the wildland fire emissions from the Total Ozone Mapping Spectrometer (TOMS) aerosol index (AI) for several regions. Schultz [2002] applied the ATSR fire counts for both seasonal and interannual variability on the wildland fire emission inventory used in the MOZART-2 chemistry transport model (described by Horowitz et al. [2003]). Van der Werf et al. [2003] recently developed an active fire count data set from the Tropical Rainfall Measuring Mission (TRMM) for the period 1998-2001. They related these fire counts to existing area burnt data from the USA and the Moderate Resolution Imaging Spectrometer (MODIS) for some regions. A modified version of the Carnegie-AmesStanford-Approach (CASA) biogeochemical model is included in this approach to obtain a wildland fire emission inventory. Another methodology for deriving location of wildland fire emissions from remote sensing data has been proposed by Govaerts et al. [2002], who related changes in surface albedo from Meteosat satellite in Africa to biomass burning.

[9] Though a big step in the right direction from the global point of view, active fire counts are not the appropriate product to make quantitative statements about global wildland fire emissions. First, the algorithms yield a noticeable number of false detections owing to their simplicity (temperature threshold) [see, e.g., Schultz, 2002]. Second, if a fire is spotted correctly, it is not possible to link this spot to the real spatial extension of the observed fire and thus to the amount of emissions released.

[10] New global fire satellite products use more sophisticated algorithms such as the Global Burnt SCAR (GLOBSCAR) data from the European Space Agency [Simon, 2002; Simon et al., 2004] or the Global Burnt Area Initiative (GBA-2000) from the Joint Research Centre of the European Commission (JRC) [Grégoire et al., 2003; Tansey et al., 2004]. These algorithms obtain area burnt in high resolution $\left(1 \mathrm{~km}^{2}\right)$, which is a crucial parameter in wildland fire emission modeling.

[11] In this paper, such a product has been analyzed with the new Global Wildland Fire Emission Model (GWEM). The presented GWEM versions are based on ESA's GLOBSCAR product, the Lund-Potsdam-Jena Global Dynamic Vegetation Model (LPJ-DGVM) [Sitch et al., 2003], and land cover maps to estimate fire emissions on the global scale. Two land cover maps, based on the same IGBP vegetation classification developed by Loveland and Belward [1997], are used: International Geosphere Biosphere Programme Data and Information System (IGBP-DIS) based on AVHRR satellite data from 1992/1993 [Loveland et al., 2000] and a more recent land cover map derived from MODIS data from 2000/2001 [Friedl et al., 2002] (available at http://duckwater.bu.edu/lc/mod12q1.html). Furthermore, GWEM includes emission factors from Andreae and Merlet [2001] and M. O. Andreae (personal communication, 2002). In summary, GWEM has become a tool which allows for a transparent calculation of emissions including seasonal and interannual variations, as adequate global high-resolution multiyear satellite input data are becoming available.

\section{Methodology}

\subsection{Calculation of Emissions}

[12] The Global Wildland Fire Emission Model (GWEM) is designed to provide global monthly inventories for more than 40 different chemical trace gases and aerosols at $0.5^{\circ} \times$ $0.5^{\circ}$ spatial resolution. The resolution limit is imposed by the input of the LPJ vegetation model. GWEM includes the following data in its calculations: (1) monthly area burnt to determine the spatial distribution of the fires and their extent within a grid box, (2) the amount of burnable plant material also known as the available fuel load (AFL) to determine the amount and exact location of carbon in the vegetation, 


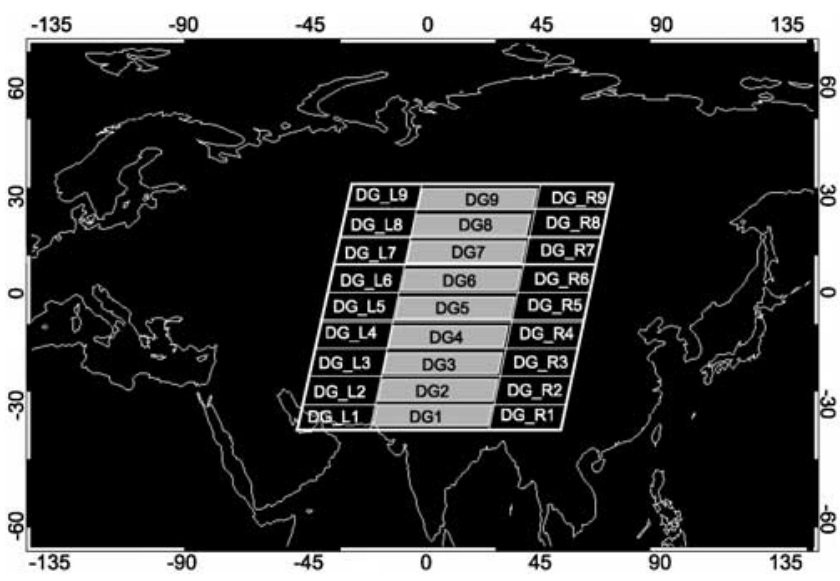

Figure 1. Schematic representation of the data gap in GLOBSCAR (regions DG1-9) in Russia and India with associated reference regions (DG_L1-9, DG_R1-9).

(3) a vegetation map which distinguishes ecosystems, (4) emission factors as a function of chemical species, and (5) the burning efficiency as a function of ecosystem which determines how much of the available fuel load is burnt. Five ecosystems have been chosen for this global approach: (1) savanna and grasslands, (2) wooded savannas, (3) tropical forests, (4) temperate forests, and (5) boreal forests.

[13] To adequately calculate the emissions for each grid box in GWEM, the very basic wildland fire emission equation $M_{\mathrm{BB}}=A \times \mathrm{AFL} \times \beta$ by Seiler and Crutzen [1980] $\left(M_{\mathrm{BB}}\right.$ is the amount of biomass burnt, $A$ is the area burnt, AFL is the available fuel load, and $\beta$ is the burning efficiency) has been extended to:

$$
M(X)=\sum_{i=1}^{m} \sum_{k=1}^{n}\left[E f_{k}(X) \times A_{i, k} \times \beta_{k} \times \mathrm{AFL}_{k}\right] .
$$

[14] $M(X)$ is the yearly total amount of species $X$ emitted from wildland fires per grid box, $m$ is the number of months ( $m=12$ ), and $n$ is the number of considered ecosystems $(n=5) . E f_{k}(X)$ is the emission factor for each species $X$ for a typical fire in ecosystem $k . A_{i, k}$ represents the area burnt per month and per ecosystem, while $\beta_{k}$ is the burning efficiency in ecosystem $k$. The information on area burnt is supplied by the GLOBSCAR product from ESA on a $1 \mathrm{~km}^{2}$ resolution. It is based on the European Remote Sensing (ERS) ATSR daytime satellite data. The AFL is from the LPJ vegetation model and is given as annual average.

\subsection{Treating Data Gaps in the Area Burnt Product}

[15] Owing to the localization of retrieval stations, the GLOBSCAR product from ESA lacks data in a few regions (see section 5). Here these areas have been corrected using ATSR nighttime active fire counts, either the IGBP or MODIS land cover map, and GLOBSCAR area burnt information in adjacent regions.

[16] First, for every data gap (DG) area, an IGBP vegetation class was attributed to each ATSR fire count. Then the data gap area was split into nine small regions (see Figure 1). Adjacent corresponding regions were chosen left (DG_L) and right (DG_R) of the data gap area for which
GLOBSCAR data were available in order to provide representative area burnt data. These latter regions were bounded by the same latitudes. The arrangement into different data gap latitude regions seems reasonable, as area burnt sizes vary between different ecosystems, which often have a latitudinal gradient. For the same reason, the average area burnt size was split into different ecosystems within the selected regions. In each region DG the average area burnt size to be attributed to each active ATSR fire count within the data gap was calculated per ecosystem:

$$
\begin{aligned}
A_{\mathrm{avrg}, \mathrm{DG}}(i, k)= & {\left[\mathrm{AB}_{\mathrm{DG} \_\mathrm{L}}(i, k)+\mathrm{AB}_{\mathrm{DG} \_\mathrm{R}}(i, k)\right] /\left[\# \mathrm{AFC}_{\mathrm{DG} \_\mathrm{L}}(i, k)\right.} \\
& \left.+\# \mathrm{AFC}_{\mathrm{DG} \_\mathrm{R}}(i, k)\right]
\end{aligned}
$$

where $i$ is the number of subregions (here 9), $k$ is the number of ecosystems (here 5), $\mathrm{AB}_{\mathrm{DG}_{-} \mathrm{L}}$ and $\mathrm{AB}_{\mathrm{DG} \mathrm{R}}$ are the number of GLOBSCAR area burnt pixels in $\mathrm{DG}_{-} \overline{\mathrm{L}}$ and DG_R, respectively, and \#AFC are the number of the respective ATSR active fire counts. In total, this method added $3254 \mathrm{~km}^{2}$ (IGBP land cover) and $3150 \mathrm{~km}^{2}$ (MODIS land cover) to the burnt area of north central Asia of $108,764 \mathrm{~km}^{2}$ (IGBP) and $87,981 \mathrm{~km}^{2}$ (MODIS) from the original GLOBSCAR data for this region.

\section{GWEM Input Data}

\subsection{Area Burnt}

[17] Until recently, information on area burnt for global needs was based exclusively on country reports providing yearly amounts of hectares burnt (e.g., the International Forest Fire News (IFFN) reports of the Food and Agriculture Organization (FAO)). The data exist only for some countries and are strongly variable in quality. This turns an application for global modeling into uncertain guesswork. Also, a countrywide approach does not allow for a sufficient resolution required for wildland fire emission modeling in terms of ecosystem distinction. Nevertheless, it was the best available for many years and has been used in several studies [e.g., Hao and Liu, 1994; Mueller, 1992; Lavoué et al., 2000].

[18] Since then, more homogeneous and higher-resolution quality data have become available and are used in regionalscale burnt area assessment [e.g., Barbosa et al., 1999; Scholes et al., 1996; Pereira et al., 1999]. However, these regional studies cannot be easily extended to the global scale, as regional data are patchy, follow different methodologies, and rely on different input.

[19] In early 2003, two global satellite products for area burnt, initially for the year 2000, became available: GBA-2000 from the Joint Research Centre (JRC) of the European Commission in Ispra, Italy, which is based on SPOT-VGT-S1 satellite data [Grégoire et al., 2003; Tansey et al., 2004] and GLOBSCAR from the European Space Agency (ESA) [Simon et al., 2004]. GLOBSCAR has been used in this study.

[20] GLOBSCAR is a freely distributed product and provides the monthly areas burnt globally at $1 \mathrm{~km}^{2}$ resolution in geographic coordinates. Upon specific request the corresponding vegetation class obtained from the IGBP land cover map (Table 1) can also be provided. The product is derived from daytime data of the Along-Track Scanning Radiometer 2 (ATSR-2) on board ESA's ERS-2 satellite and 
Table 1. International Geosphere Biosphere Programme (IGBP) Land Cover Classification as Described in the Work of Loveland and Belward [1997], GWEM Ecosystem Assignment, and Andreae and Merlet [2001] Ecosystem Assignment

\begin{tabular}{|c|c|c|c|c|c|}
\hline Value & Vegetations Classes & Value & GWEM Ecosystems & Value & Andreae and Merlet [2001] Ecosystems \\
\hline 1 & evergreen needleleaf forest & 4,5 & forest, latitude-dependent ${ }^{\mathrm{a}}$ & 2,3 & forest, latitude-dependent ${ }^{\mathrm{b}}$ \\
\hline 2 & evergreen broadleaf forest & 3,4 & 3: tropical forest & & \\
\hline 3 & deciduous needleleaf forest & 4,5 & 4: temperate forest & & \\
\hline 4 & deciduous broadleaf forest & 3,4 & 5: boreal forest & & \\
\hline 5 & mixed forest & $3,4,5$ & & & \\
\hline 6 & closed shrublands & 2 & woody savanna & 1 & savanna and grasslands \\
\hline 7 & open shrublands & 2 & & & \\
\hline 8 & woody savannas & 2 & & & \\
\hline 9 & savannas & 1 & savanna and grasslands & & \\
\hline 10 & grasslands & 1 & & & \\
\hline 11 & permanent wetlands & 2 & woody savanna & & \\
\hline 12 & croplands & - & - & - & - \\
\hline 13 & urban and built-up & - & - & - & - \\
\hline 14 & cropland/natural vegetation mosaic & 2 & woody savanna & 1 & savanna and grasslands \\
\hline 15 & snow and ice & - & - & - & - \\
\hline 16 & barren or sparsely vegetated & 1 & savanna and grasslands & 1 & savanna and grasslands \\
\hline 17 & water bodies & - & - & - & - \\
\hline 99 & interrupted areas (projection) & - & - & - & - \\
\hline 100 & missing data & - & - & - & - \\
\hline
\end{tabular}

${ }^{\text {a}}$ Here $3,\left[-30^{\circ},+30^{\circ}\right] ; 5,\left[<-60^{\circ}\right.$ and $\left.>+60^{\circ}\right] ; 4$, other.

${ }^{\mathrm{b}}$ Here 2, tropical forest; 3 , extratropical forest.

relies on two complementary algorithms. The first one (K1) [Arino et al., 2000] determines area burnt pixels by a value obtained from combination of low reflectance and increased brightness temperature typical for burnt areas, whereas the second one (E1) [Eva and Lambin, 1998a, 1998b] consists of a set of fixed threshold tests applied to the data.

[21] In this study a subselection of the forest and savanna fires in the GLOBSCAR data set has been used together with the IGBP-DIS land cover map (in GWEM1.20 ), or respectively, the MODIS land cover map (in GWEM-1.21). Figure 2 provides the monthly global burnt area as given by GLOBSCAR for vegetated nonagricultural land cover classes according to both land cover maps. In total, a global area of $1.71 \times 10^{6} \mathrm{~km}^{2}$ and $1.73 \times 10^{6}$ for IGBP and MODIS, respectively, burnt in forest and savanna fires in the year 2000. Both land cover maps are used in GWEM to determine the emission factors and burning efficiencies, which vary between different vegetation types. GLOBSCAR records with IGBP classes 1-11 and 14 were considered. Classes 12, 13, and 15-17 were eliminated owing to their unburnable nature or inadequate biomass burning category, such as crops (class 12), which are not regarded here. From the total of $2.01 \times 10^{6} \mathrm{~km}^{2}$ detected GLOBSCAR area burnt, $310,000 \mathrm{~km}^{2}$ (IGBP) and $280,000 \mathrm{~km}^{2}$ (MODIS) of burnt cropland (class 12) were eliminated from the record. For a detailed description, see Simon et al. [2004]. Online information on GLOBSCAR can be found at the ESA Web site http://earth.esa.int/ionia.

\subsection{Available Fuel Load}

[22] Equally crucial input data for wildland fire emission modeling are the information on potentially burnable vegetation (also known as available fuel load (AFL)). There are three different approaches pursued in the literature so far. Most common for wildland fire emission modeling are compiled fuel load maps (e.g., ECE-FAOs, IFFN reports, or literature in the works of, e.g., Lavoué et al. [2000] and Hao and Liu [1994]). These prescribed fuel load values are representative for ecosystems in a specific region but cannot be applied on a global scale. To the authors' knowledge, there are currently no globally consistent and accurate data on AFL in the literature which can be used for emission modeling.

[23] In regional approaches, satellite-retrieved vegetation specific parameters such as the normalized difference vegetation index (NDVI) for Africa have been used to compute the AFL [e.g., Barbosa et al., 1999]. This remote sensing approach, however, requires detailed background knowledge about each particular region under investigation. A third approach for estimating AFL is the use of vegetation models simulating the global carbon cycle within the terrestrial biosphere. These models calculate different carbon pools within the vegetation, and by choice of the essential ones (which are susceptible to fire) the AFL can be determined. On the regional scale, Hély et al. [2003b] have used a fuel

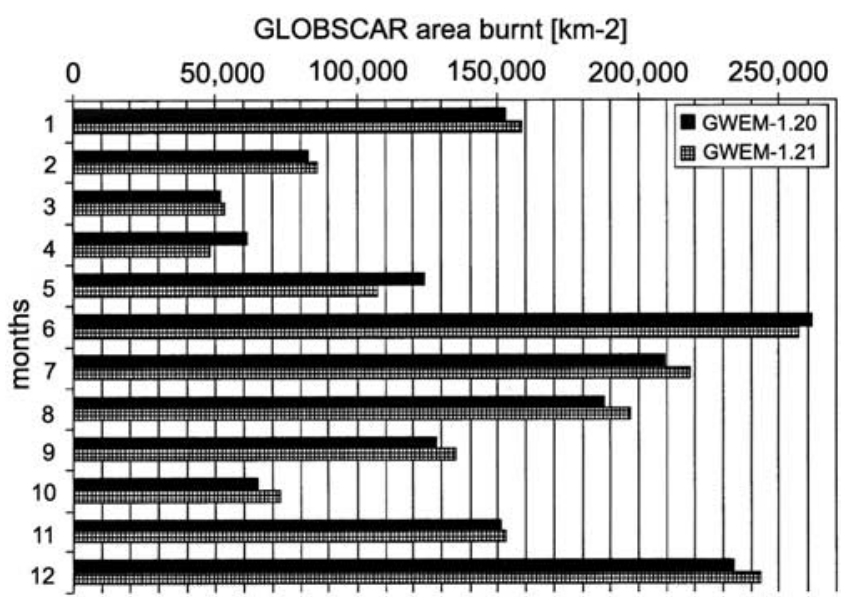

Figure 2. GLOBSCAR global monthly area burnt by wildland fires in $\mathrm{km}^{2}$ for the year 2000. In both the GWEM1.20 (IGBP-based) and the GWEM-1.21 (MODIS-based) run, IGBP vegetation classes greater than 12 (except for 14) are excluded. 
Table 2. Regional Totals of Averaged Available Fuel Load (AFL) per Ecosystem as Calculated by GWEM-1.20 and GWEM-1.21 in $\mathrm{g} / \mathrm{m}^{2}$, Compared With Average AFL From Literature ${ }^{\mathrm{a}}$

\begin{tabular}{|c|c|c|c|c|c|}
\hline Region & $\begin{array}{c}\text { GWEM-1.20 } \\
\text { Average AFL } \\
\text { Savanna Type, } \mathrm{g} / \mathrm{m}^{2}\end{array}$ & $\begin{array}{c}\text { GWEM-1.20 } \\
\text { Average AFL } \\
\text { Forest Type, } \mathrm{g} / \mathrm{m}^{2}\end{array}$ & $\begin{array}{c}\text { GWEM-1.21 } \\
\text { Average AFL } \\
\text { Savanna Type, } \mathrm{g} / \mathrm{m}^{2}\end{array}$ & $\begin{array}{c}\text { GWEM-1.21 } \\
\text { Average AFL } \\
\text { Forest Type, } \mathrm{g} / \mathrm{m}^{2}\end{array}$ & $\begin{array}{c}\text { Literature } \\
\text { Average AFL, } \\
\mathrm{g} / \mathrm{m}^{2}\end{array}$ \\
\hline North America & $\begin{array}{l}947^{\mathrm{b}}(883-1075) \\
5853^{\mathrm{c}}(5476-6606)\end{array}$ & $\begin{array}{l}28,322^{\mathrm{d}}(11,037-34,666) \\
10,089^{\mathrm{e}}(9312-11,644) \\
11,809^{\mathrm{f}}(10,166-14,706)\end{array}$ & $\begin{array}{l}1004^{\mathrm{b}}(941-1131) \\
5557^{\mathrm{c}}(5199-6273)\end{array}$ & $\begin{array}{l}27,829^{\mathrm{d}}(10,309-33,817) \\
10,894^{\mathrm{e}}(10,057-12,568) \\
12,462^{\mathrm{f}}(10,732-15,537)\end{array}$ & $\begin{array}{l}10,000^{\mathrm{e}, \mathrm{g}}-38,000^{\mathrm{e}, \mathrm{h}} \\
2590^{\mathrm{f}, \mathrm{i}}-3720^{\mathrm{f}, \mathrm{i}}\end{array}$ \\
\hline Central America & $\begin{array}{l}410^{\mathrm{b}}(362-508) \\
2252^{\mathrm{c}}(2025-2705)\end{array}$ & $\begin{array}{l}19,700^{\mathrm{d}}(9102-20,584) \\
870^{\mathrm{e}}(785-1039)\end{array}$ & $\begin{array}{l}425^{\mathrm{b}}(375-525) \\
2196^{\mathrm{c}}(1984-2618)\end{array}$ & $\begin{array}{l}20,820^{\mathrm{d}}(9438-21,864) \\
1231^{\mathrm{e}}(1115-1464)\end{array}$ & \\
\hline South America & $\begin{array}{l}540^{\mathrm{b}}(471-678) \\
3080^{\mathrm{c}}(2753-3733)\end{array}$ & $\begin{array}{l}25,811^{\mathrm{d}}(9344-27,133) \\
6173^{\mathrm{e}}(5471-7576)\end{array}$ & $\begin{array}{l}563^{\mathrm{b}}(496-696) \\
3074^{\mathrm{c}}(2746-3729)\end{array}$ & $\begin{array}{l}25,507^{\mathrm{d}}(9533-26,661) \\
5743^{\mathrm{e}}(5014-7200)\end{array}$ & $\begin{array}{l}710-6600^{\mathrm{b}, \mathrm{c}, \mathrm{j}} \\
12,000-43,500^{\mathrm{d}, \mathrm{k}}\end{array}$ \\
\hline Northern Africa & $\begin{array}{l}311^{\mathrm{b}}(261-411) \\
2469^{\mathrm{c}}(2137-3134)\end{array}$ & $\begin{array}{l}26,537^{\mathrm{d}}(10,067-28,106) \\
3522^{\mathrm{e}}(3145-4275)\end{array}$ & $\begin{array}{l}324^{\mathrm{b}}(274-426) \\
2532^{\mathrm{c}}(2192-3213)\end{array}$ & $\begin{array}{l}24,194^{\mathrm{d}}(8636-26,352) \\
3471^{\mathrm{e}}(3140-4132)\end{array}$ & \\
\hline Southern Africa & $\begin{array}{l}357^{\mathrm{b}}(306-459) \\
2500^{\mathrm{c}}(2181-3138)\end{array}$ & $\begin{array}{l}23,886^{\mathrm{d}}(8587-25,614) \\
6048^{\mathrm{e}}(5358-7430)\end{array}$ & $\begin{array}{l}363^{\mathrm{b}}(310-468) \\
2466^{\mathrm{c}}(2150-3096)\end{array}$ & $\begin{array}{l}26,703^{\mathrm{d}}(10,049-28,441) \\
6152^{\mathrm{e}}(5629-7198)\end{array}$ & $250-734^{\mathrm{b}, \mathrm{c}, 1}$ \\
\hline Western Europe & $\begin{array}{l}1753^{\mathrm{b}}(1677-1906) \\
4452^{\mathrm{c}}(4137-5081)\end{array}$ & $\begin{array}{l}6690^{\mathrm{e}}(5715-8640) \\
5803^{\mathrm{f}}(4992-7084)\end{array}$ & $\begin{array}{l}889^{\mathrm{b}}(833-1000) \\
4593^{\mathrm{c}}(4293-5195)\end{array}$ & $\begin{array}{l}7549^{\mathrm{e}}(6627-9993) \\
6653^{\mathrm{f}}(5430-8770)\end{array}$ & \\
\hline Eastern Europe & $\begin{array}{l}1267^{\mathrm{b}}(1206-1391) \\
7130^{\mathrm{c}}(6692-8005)\end{array}$ & $\begin{array}{l}10,937^{\mathrm{e}}(9916-12,979) \\
8556^{\mathrm{f}}(7696-9869)\end{array}$ & $\begin{array}{l}1456^{\mathrm{b}}(1399-1570) \\
8374^{\mathrm{c}}(7979-9164)\end{array}$ & $\begin{array}{l}11,834^{\mathrm{e}}(10,844-13,812) \\
7736^{\mathrm{f}}(7133-8501)\end{array}$ & \\
\hline North central Asia & $\begin{array}{l}2187^{\mathrm{b}}(2104-2353) \\
10,364^{\mathrm{c}}(9970-11,150)\end{array}$ & $\begin{array}{l}19,872^{\mathrm{e}}(18,774-22,067) \\
12,006^{\mathrm{f}}(10,413-14,871)\end{array}$ & $\begin{array}{l}2152^{\mathrm{b}}(2071-2314) \\
11,654^{\mathrm{c}}(11,273-12,416)\end{array}$ & $\begin{array}{l}21,742^{\mathrm{e}}(20,713-23,798) \\
11,298^{\mathrm{f}}(9709-14,109)\end{array}$ & $5000^{\mathrm{f}, \mathrm{m}}$ \\
\hline Near East & $\begin{array}{l}708^{\mathrm{b}}(666-792) \\
2986^{\mathrm{c}}(2826-3305)\end{array}$ & $8145^{\mathrm{e}}(7452-9532)$ & $\begin{array}{l}602^{\mathrm{b}}(565-676) \\
2906^{\mathrm{c}}(2748-3221)\end{array}$ & $\begin{array}{l}6181^{\mathrm{d}}(3341-6181) \\
12,486^{\mathrm{e}}(11,583-14,291)\end{array}$ & \\
\hline East Asia & $\begin{array}{l}893^{b}(824-1031) \\
4520^{c}(4131-5300)\end{array}$ & $6890^{\mathrm{e}}(6133-8402)$ & $\begin{array}{l}551^{\mathrm{b}}(493-667) \\
4063^{\mathrm{c}}(3683-4823)\end{array}$ & $8840^{\mathrm{e}}(8060-10,398)$ & \\
\hline Southern Asia & $\begin{array}{l}1781^{\mathrm{b}}(1701-1940) \\
4834^{\mathrm{c}}(4479-5544)\end{array}$ & $\begin{array}{l}27,030^{\mathrm{d}}(10,408-30,242) \\
14,629^{\mathrm{e}}(13,665-16,558)\end{array}$ & $\begin{array}{l}1108^{\mathrm{b}}(1235-1453) \\
5222^{\mathrm{c}}(4874-5920)\end{array}$ & $\begin{array}{l}28,908^{\mathrm{d}}(12,025-32,4353) \\
16,922^{\mathrm{e}}(15,981-18,802)\end{array}$ & \\
\hline Oceania & $\begin{array}{l}238^{\mathrm{b}}(206-302) \\
1273^{\mathrm{c}}(1126-1566)\end{array}$ & $\begin{array}{l}15,802^{\mathrm{d}}(7532-16,494) \\
6790^{\mathrm{e}}(6016-8337)\end{array}$ & $\begin{array}{l}251^{\mathrm{b}}(216-320) \\
1269^{\mathrm{c}}(1121-1564)\end{array}$ & $\begin{array}{l}16,950^{\mathrm{d}}(6495-17,580) \\
7015^{\mathrm{e}}(6187-8671)\end{array}$ & \\
\hline
\end{tabular}

${ }^{a}$ From J. S. Reid (manuscript in preparation, 2003).

${ }^{\mathrm{b}}$ Savanna and grasslands.

${ }^{\mathrm{c}}$ Wooded savanna.

${ }^{\mathrm{d}}$ Tropical forest.

${ }^{\mathrm{e}}$ Temperate forest.

${ }^{\mathrm{f}}$ Boreal forest.

${ }^{\mathrm{g}}$ Oregon, USA, Hobbs et al. [1996].

${ }^{\mathrm{h}}$ Washington, USA, Hobbs et al. [1996].

${ }^{\mathrm{i}}$ North America, Kasischke and Bruhwiler [2002].

${ }^{\mathrm{j}}$ Brazil, Ward et al. [1992] and Guild et al. [1998].

kBrazil, Ward et al. [1992], Kauffman et al. [1995], and Guild et al. [1998]

${ }^{1}$ South Africa, Stocks et al. [1996] and Trollope and Trollope [1996]. Zambia, Shea et al. [1996].

${ }^{\mathrm{m}}$ Siberia, Russia, FIRESCAN Science Team [1996].

load model for southern Africa, while van der Werf et al. [2003] have applied the biogeochemical CASA model for emission modeling in the tropics and subtropics.

[24] In this work, output of the Lund-Potsdam-Jena Dynamic Global Vegetation Model (LPJ-DGVM) [Sitch et al., 2003] is used for estimating the AFL. LPJ is considered a model of intermediate complexity, which can be applied to a broad range of global applications. LPJ simulates processbased large-scale terrestrial vegetation dynamics including the carbon exchange between land, atmosphere, and water. For a more detailed description, see Sitch et al. [2003]. LPJ delivers global annual carbon pools of litter, leaf, wood, and fine roots at a $0.5^{\circ} \times 0.5^{\circ}$ resolution. For this study, carbon pools as calculated by the model were averaged over the 1991-1998 period, as no clear trend or strong variation could be seen in the LPJ model output and no specific simulation was available for the year 2000. A comparison of the AFL used in GWEM and corresponding literature values for five major ecosystems can be found in Table 2 .

[25] Three different scenarios were computed. A best guess run that includes the best estimate of the AFL according to literature and input from various experts. To get a first idea about the sensitivity of GWEM toward the
AFL, a minimum and a maximum run were additionally performed. The minimum run uses $50 \%$ of the AFL in the best guess run, while the AFL in the maximum run is doubled compared to the best guess (Table 3).

[26] The outcome of these two extreme runs is used as a range on the best guess results of GWEM. Table 3 presents

Table 3. Percentage of Biomass per Carbon Pool and Ecosystem That is Available for Combustion ${ }^{\text {a }}$

\begin{tabular}{|c|c|c|c|c|}
\hline \multirow[b]{2}{*}{ Ecosystems } & \multicolumn{4}{|c|}{ LPJ Carbon Pools } \\
\hline & Litter & Leaf & Wood & Fine Roots \\
\hline Savanna and grasslands & 100 & $50(25-100)$ & $5(2.5-10)$ & 0 \\
\hline Wooded savanna & 100 & $20(10-40)$ & $5(2.5-10)$ & 0 \\
\hline $\begin{array}{l}\text { Tropical forest, } \\
\text { undisturbed, dry }\end{array}$ & 100 & $10(5-20)$ & 0 & 0 \\
\hline $\begin{array}{l}\text { Tropical forest, } \\
\text { moderately disturbed }\end{array}$ & 100 & $50(25-100)$ & $20(10-40)$ & 0 \\
\hline $\begin{array}{l}\text { Tropical forest, } \\
\text { heavily disturbed }\end{array}$ & 100 & $80(40-160)$ & $30(15-60)$ & 0 \\
\hline Temperate forest & 100 & $30(15-60)$ & $10(5-20)$ & 0 \\
\hline Boreal forest, Eurasia & 70 & $20(10-40)$ & $20(10-40)$ & $5(2.5-10)$ \\
\hline Boreal forest, America & 100 & $10(5-20)$ & $30(15-60)$ & $5(2.5-10)$ \\
\hline
\end{tabular}

${ }^{\mathrm{a}}$ From J. G. Goldammer (personal communication, 2002); values for minimum and maximum run are in parentheses. 

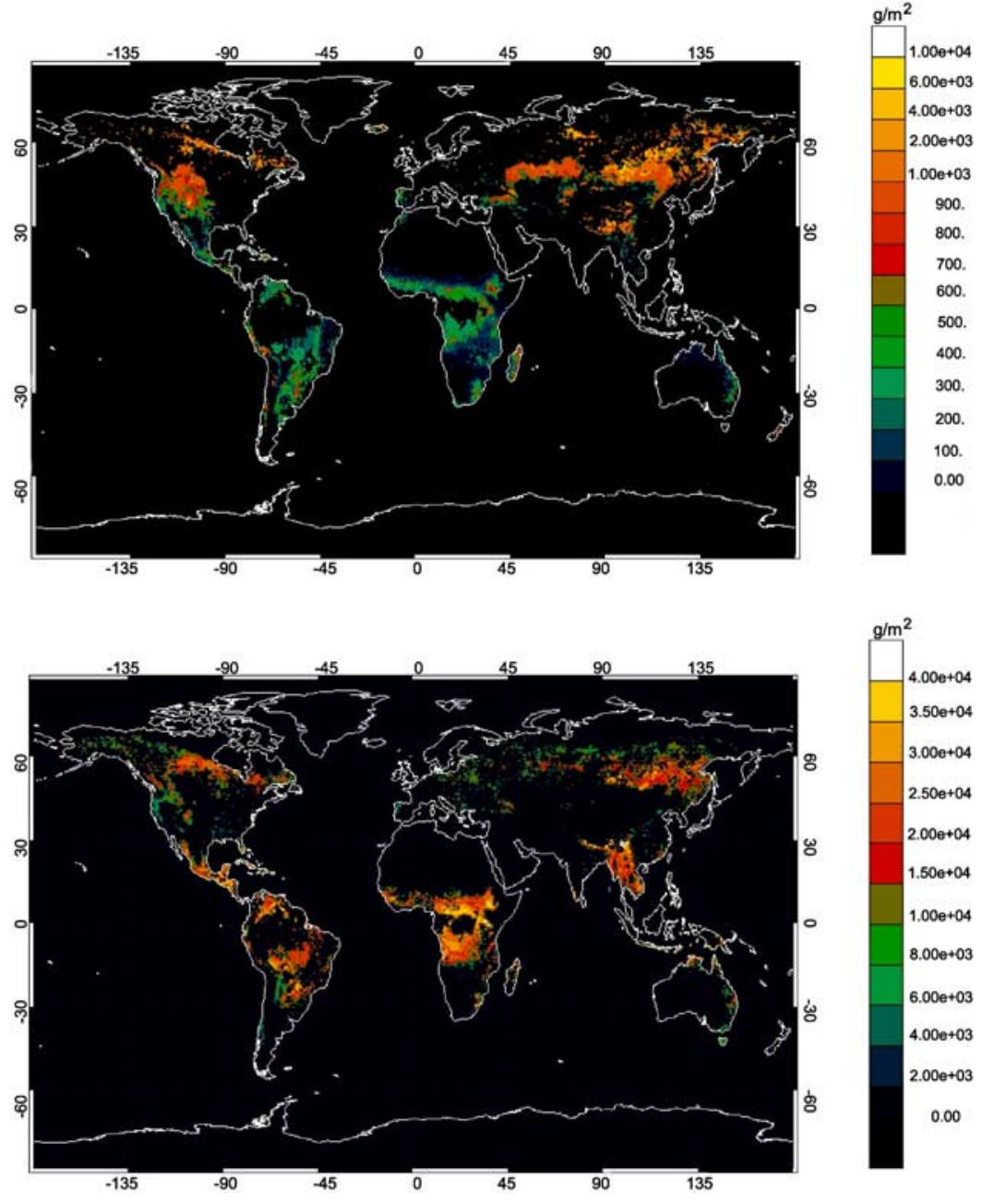

Figure 3. Global available fuel load (AFL) in $\left[\mathrm{g} / \mathrm{m}^{2}\right]$ for GWEM-1.21 based on averaged input data of the LPJ vegetation model for the year 1991-1998 and the MODIS land cover scheme. Only AFL at GLOBSCAR area burnt locations is shown. (top) AFL for ecosystem savanna and grasslands. (bottom) AFL for all forest ecosystems.

the percentage of the biomass provided by the LPJ model, which is susceptible to fire (AFL percentage (Ap)). The numbers are valid for the best guess run, while the values in parentheses were used for the minimum and maximum run, respectively.

[27] In all ecosystems, litter is potentially fully available for burning. In forest ecosystems, mainly the litter layer (dead needles and leaves, downed woody material) and small live and dead aerial fuels (foliage, twigs, small branches of under-story vegetation and trees) are consumed by fire; depending on dryness conditions, the duff layer is also available for partial or complete combustion [FIRESCAN Science Team, 1996; J. G. Goldammer, personal communication, 2002]. However, there are differences for forests in different climatic zones and continents. In Eurasia, for example, less litter (only $70 \%$ of total) is available for fire because of the thickness and moisture content in raw humus layers during average fire-weather conditions [FIRESCAN Science Team, 1996; J. G. Goldammer, personal communication, 2002].

[28] An even more difficult case for generalization is the tropical forest: depending on its deforestation history, it is variably susceptible to fire [Goldammer, 1999]. If a tropical forest is undisturbed but dry and ready for a fire, the litter burns, but trees remain almost unaffected, and only a minor percentage of the leafs can burn. If the tropical forest is moderately disturbed, half of the leaf and a small part of the wood pool can potentially burn in addition to the total litter, while in heavily disturbed tropical forest, a considerable part of the leaf and decaying wood pool can be affected apart from the litter (J. G. Goldammer, personal communication, 2002).

[29] Thus the total AFL per grid box is given by:

$$
\mathrm{AFL}_{\mathrm{tot},}=\sum_{n=1}^{5} \sum_{k=1}^{4}\left[\mathrm{Ap}_{n k} \times B_{k}\right]
$$

where $n$ is the ecosystem, $k$ is the carbon pool, $\mathrm{Ap}_{n k}$ are the percentages of the AFL in Table 3 , and $B_{k}$ is the LPJ biomass density for each carbon pool and grid box.

[30] The global distribution of AFL for this run can be found in Figure 3. The upper panel shows the AFL of fires in the GWEM ecosystems savanna and grasslands and 
Table 4. Emission Factors for Three Different Biomes Used in GWEM $^{\mathrm{a}}$

\begin{tabular}{|c|c|c|c|c|c|c|}
\hline \multirow[b]{2}{*}{ Compound } & \multicolumn{3}{|c|}{$\begin{array}{c}\text { Emission Factor, } \\
\text { g species/kg dry matter }\end{array}$} & \multicolumn{3}{|c|}{$\begin{array}{l}\text { Standard } \\
\text { Deviation }\end{array}$} \\
\hline & $\begin{array}{c}\text { Savanna } \\
\text { and Grasslands }\end{array}$ & $\begin{array}{l}\text { Tropical } \\
\text { Forest }\end{array}$ & $\begin{array}{c}\text { Extratropical } \\
\text { Forest } \\
\end{array}$ & 1 & 2 & 3 \\
\hline $\mathrm{CO}_{2}$ & 1663 & 1580 & 1569 & 88 & 90 & 131 \\
\hline $\mathrm{CO}$ & 61.6 & 103.2 & 106.7 & 16.2 & 18.9 & 37.1 \\
\hline $\mathrm{CH}_{4}$ & 2.20 & 6.80 & 4.70 & 0.80 & 2.00 & 1.90 \\
\hline NMHC & 3.40 & 8.10 & 5.70 & 1.00 & 3.00 & 4.60 \\
\hline $\mathrm{NO}_{x}$ & 2.32 & 1.85 & 3.00 & 0.97 & 0.76 & 1.45 \\
\hline $\mathrm{SO}_{2}$ & 0.71 & 0.57 & 1.00 & 0.82 & 0.23 & $-b$ \\
\hline $\mathrm{PM}_{2.5}$ & 4.90 & 9.10 & 12.99 & 1.50 & 1.50 & 6.95 \\
\hline TPM & 9.20 & 8.50 & 17.62 & 3.90 & 2.90 & 6.36 \\
\hline TEC & 3.70 & 6.60 & 8.28 & 1.20 & 1.50 & 3.05 \\
\hline $\mathrm{OC}$ & 3.30 & 5.20 & 9.14 & 1.30 & 1.50 & 0.83 \\
\hline $\mathrm{BC}$ & 0.47 & 0.66 & 0.56 & 0.17 & 0.31 & 0.19 \\
\hline
\end{tabular}

${ }^{\mathrm{a}}$ According to Andreae and Merlet [2001] and M. O. Andreae (personal communication, 2002).

${ }^{\mathrm{b}}$ Only one value in literature for this species; therefore no standard deviation.

wooded savannas, and on the bottom panel is the AFL for fires that burn in the GWEM ecosystems tropical forest, temperate forest, and boreal forest.

\subsection{Emission Factors}

[31] A broad range of publications on emissions from biomass burning exists from various field campaigns and some laboratory studies. For a global approach, which includes many ecosystems, the use of average values based on many different sources seems to be the most appropriate way. In addition, emission factors vary as the fire season progresses owing to changing moisture conditions. Unfortunately, information necessary to quantify this effect is only available for limited regions.

[32] Emission factors in this paper are based on the publication of Andreae and Merlet [2001] with several updates (M. O. Andreae, personal communication, 2002) (Table 4). Values and standard deviation are given on the basis of a collection of emission factors for about 90 species from field campaigns in about 130 publications. Emission factors in this paper are given for the three different ecosystems: (1) savanna and grasslands, (2) tropical forest, and (3) extratropical forest. The extension to the five ecosystems used in GWEM is listed in Table 1. Emission factors are averaged and constant throughout the year, independent of the wet (early) or dry (late) fire season.

\subsection{Burning Efficiency}

[33] The burning efficiency or combustion fraction in GWEM is taken from J. S. Reid et al. (manuscript in preparation, 2003), who have based their recommendations on several different publications for various regions and ecosystems [FIRESCAN, 1996; Guild et al., 1998; Hobbs et al., 1996; Kauffman et al., 1995, 1998; Shea et al., 1996; Stocks et al., 1996; Trollope and Trollope, 1996; Ward and Hao, 1992; Ward et al., 1996]. The combustion fraction is kept invariant to changes in fuel moisture and therefore does not change during the annual cycle. Values are available for the five different ecosystems in the work of J. S. Reid (manuscript in preparation, 2003), which are identical to those used in GWEM
(Table 5). The uncertainties listed in this table are further discussed in section 6 .

\subsection{Active Fire Counts}

[34] Active fire counts have only been used in this work for handling the data gap of the GLOBSCAR product in central Russia and India. Available products on the global scale are, e.g., active fire detections by MODIS (since May 2001) and the ATSR World Fire Atlas (August 1996 to February 2002). In this work, fire counts for the year 2000 were needed, and therefore the ATSR data from ESA have been used. The ATSR fire counts are processed using nighttime data $(\sim 2200$ LT) from the infrared channel (3.7 microns). If a threshold of 308 or $312 \mathrm{~K}$ is exceeded (two different algorithms), the observed pixel is declared as burning. In this paper the product of the $308 \mathrm{~K}$ threshold algorithm is applied to the emission inventory for the year 2000 except for fire pixels which were declared as spurious, which means they are hot pixels, but not from wildland fires. These overdetections result from oil exploration gas flares and cities, but these can easily be eliminated. Other than uncontrolled burning events, these kind of fires are permanently seen by the sensors and can therefore be identified if the fire is located at the same spot during over $60 \%$ of the year [Schultz, 2002].

[35] However, omission can occur for low-temperature fires, such as peat fires, which are missed owing to the temperature threshold of the product. For further information, see the Validation Report of the ATSR World Fire Atlas by Arino and Plummer [2001].

\section{Results}

[36] Results of a "best guess" run with the Global Wildland Fire Emission Model (GWEM) are shown here: Figure 4 shows the monthly integrated global emission flux of $\mathrm{CO}$ in $\mathrm{g} / \mathrm{m}^{2}$ for the months March, June, September, and December of the year 2000 at a $0.5^{\circ} \times 0.5^{\circ}$ spatial resolution. A specific seasonality in each continental region can be observed. The uncertainty of the calculated values stems from the minimum and maximum AFL runs (see section 3.2).

[37] The ratio of $\mathrm{NO}_{x} / \mathrm{CO}$ averaged over the year 2000 is shown in Figure 5. The $\mathrm{NO}_{x} / \mathrm{CO}$ ratio varies from 0 to about 0.037 depending on the ecosystem. Lowest values can be observed in the forest ecosystems (e.g., Africa and Brazil but also boreal regions), while savannas and grasslands (e.g., Africa, Mongolia, Brazilian Cerrado, Australia, etc.) show a higher ratio of $\mathrm{NO}_{x} / \mathrm{CO}$. The ratio of the latter

Table 5. Burning Efficiencies Used in GWEM in $\mathrm{g} / \mathrm{m}^{2}$ and Uncertainties $^{\mathrm{a}}$

\begin{tabular}{lcc}
\hline \multicolumn{1}{c}{ Ecosystem } & Burning Efficiency $\beta$ & Uncertainty \\
\hline Savanna and grassland & 0.85 & 0.1 \\
Woody savanna & 0.6 & 0.1 \\
Boreal forest & 0.5 & 0.1 \\
Tropical forest & 0.5 & 0.1 \\
Temperate forest & 0.5 & 0.1 \\
\hline
\end{tabular}

${ }^{\mathrm{a}}$ From a compilation by J. S. Reid (manuscript in preparation, 2003). For references, see section 3.4. 

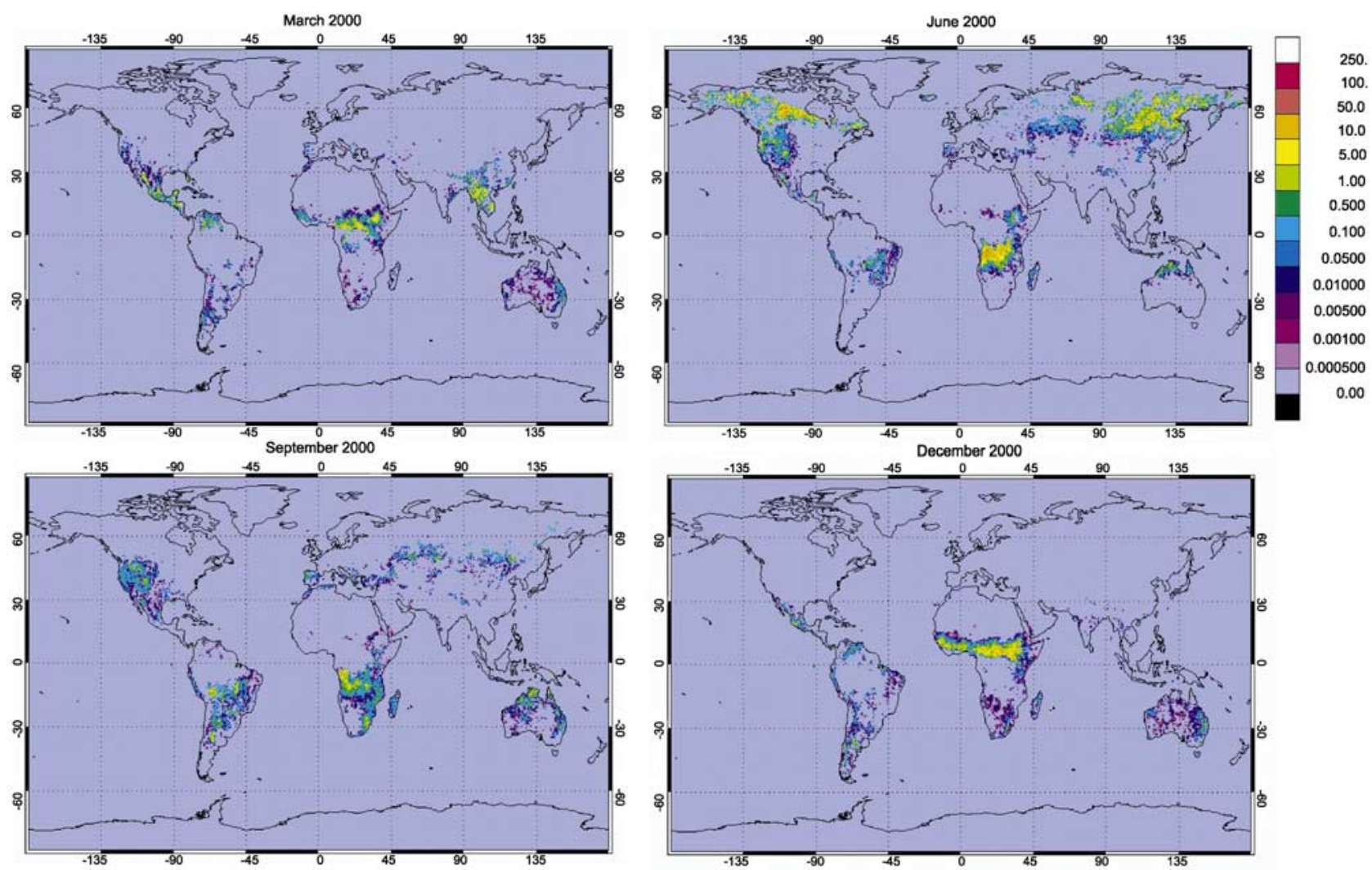

Figure 4. Global monthly $\mathrm{CO}$ wildland fire emissions in $\mathrm{g} / \mathrm{m}^{2}$ calculated by GWEM-1.21 for the months March, June, September, and December 2000 on the basis of MODIS land cover.

is higher because of the more complete combustion in flaming fires, which reduces the amount of $\mathrm{CO}$ emitted relative to $\mathrm{NO}_{x}$ and $\mathrm{CO}_{2}$. In total, GWEM-1.21 computes 1741 (1365-2028) Tg C, 5716 (4502-6667) $\mathrm{Tg} \mathrm{CO}_{2}, 271$ $(202-311) \mathrm{Tg} \mathrm{CO}, 12.52(8.51-14.19) \mathrm{Tg} \mathrm{CH}_{4}$, 9.09 (11.75-19.06) Tg C as NMHC, 8.08 (6.54-9.42) Tg $\mathrm{NO}_{\mathrm{x}}$ (as NO), $24.30(18.30-27.80) \mathrm{Tg} \mathrm{PM}_{2.5}, 15.80$ $(12.21-18.11) \mathrm{Tg} \mathrm{OC}$, and $1.84(1.39-2.13) \mathrm{Tg} \mathrm{BC}$ as wildland fire emissions for the year 2000 .
[38] To obtain a more detailed idea about regional emission behavior, 12 regions were defined (Figure 6), and the emissions in these regions were analyzed in terms of their amount, uncertainty, and seasonality. A more detailed description of the defined regions in Figure 6 is given in Table 6 , where the countries in each region are listed.

[39] Figure 7 visualizes the seasonal variation of the wildland fire $\mathrm{CO}$ emissions for 9 of these 12 regions as

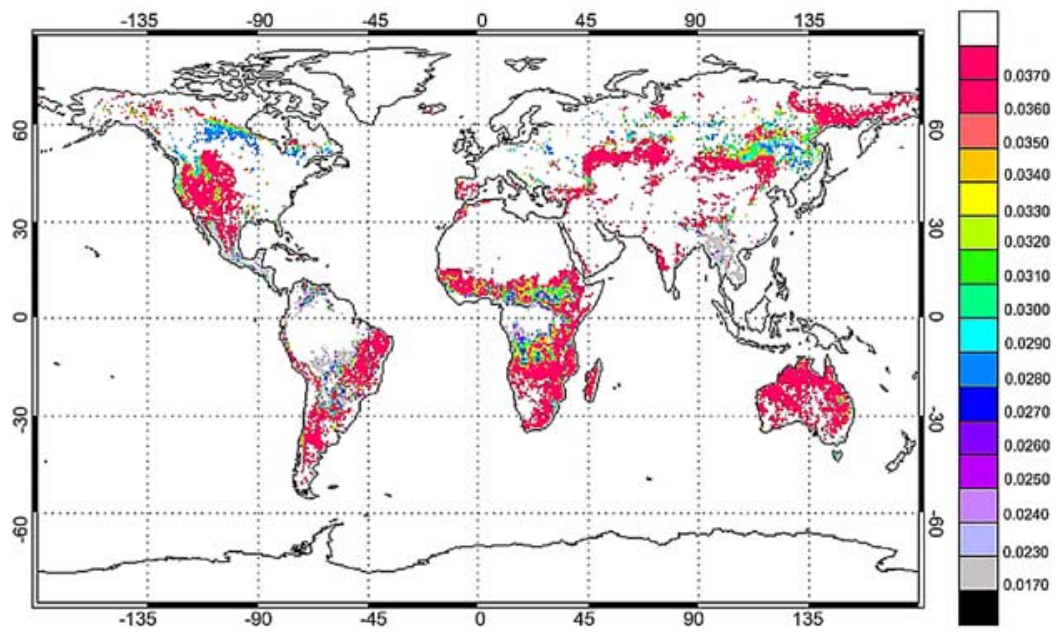

Figure 5. Global annual average $\mathrm{NO}_{x} / \mathrm{CO}$ ratio of fire emissions calculated by GWEM for the year 2000 on the basis of MODIS land cover. 


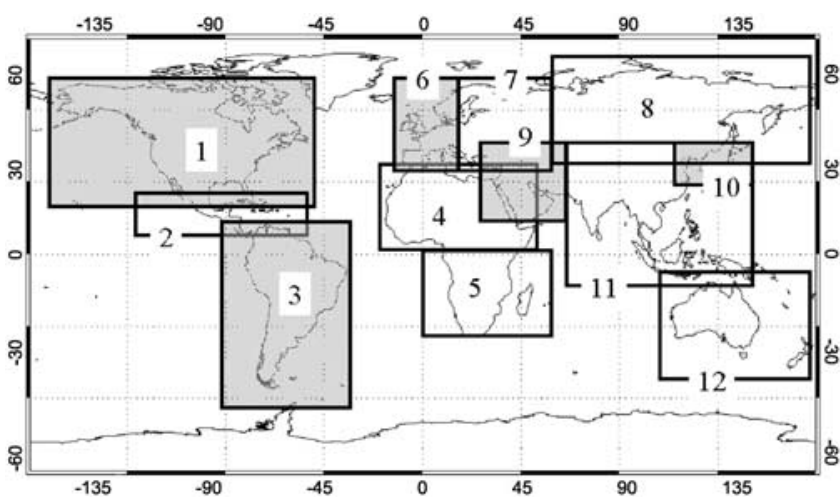

Figure 6. Geographical regions used for regional emission analysis in GWEM.

computed by GWEM-1.20 and GWEM-1.21 for the year 2000. Owing to the high variability of emissions, the figure is broken down in two diagrams: in Figure 7a the main emitter regions are shown for GWEM-1.20 (IGBP land cover map based) above and GWEM-1.21 (MODIS land cover map based) below. The most remarkable difference in these two runs is the graph for southern Africa. GWEM-1.20, which is based on the IGBP land cover map, calculates about five times as much $\mathrm{CO}$ in June as GWEM-1.21 based on the MODIS land cover map. This is solely caused by the highly differing ecosystem assignments between these two maps (see discussion section). In all other regions, no striking differences in the monthly totals can be observed.

[40] The regions North America, southern Africa, and north central Asia show a peak of the fire season in June. The fire seasons extend from May to September for North America, from April to October in southern Africa, and from April to September in north central Asia. In northern Africa the fire season extends from November to April, reaching its maximum in December. These four main regions account for most of the features of the global curve shown in Figure $7 \mathrm{a}$.

[41] In Figure 7b a much smaller contribution is found for the regions Eastern Europe, southern Asia, Oceania, South America, and Central America: the maximum monthly emissions for carbon monoxide are from southern Asia in March 2000. The remarkable difference in seasonality and $\mathrm{CO}$ emissions in Eastern Europe between the two model versions is explained by the incorrect assignment of agricultural areas as wooded savannas in the IGBP data set.

[42] A look at the annual totals of $\mathrm{CO}$ and $\mathrm{NO}_{x}$ (as $\mathrm{NO}$ ) is provided in Figure 8. Again, there are two subdiagrams containing the same regions. The highest contributor to the annual global amount of $516 \mathrm{Tg} \mathrm{CO}$ and $12.74 \mathrm{Tg} \mathrm{NO}_{x}$ for GWEM-1.20 is southern Africa with $274 \mathrm{Tg} \mathrm{CO}$ and $5.36 \mathrm{Tg} \mathrm{NO}$. This represents more than 50 and $40 \%$ of the global numbers for $\mathrm{CO}$ and $\mathrm{NO}_{x}$, respectively. GWEM-1.21 emits only around $25 \%$ of $\mathrm{CO}$ and $\mathrm{NO}_{x}$ in this region (see section 5.2). Southern Africa, northern Africa, and north central Asia yield emissions of about the same order in both versions. All numbers can be found in Table 7 (monthly values), Table 8 (regional totals $\mathrm{CO}$ ), and Table 9 (regional totals $\mathrm{NO}_{x}$ ).

[43] Total monthly emissions of $\mathrm{CO}$ for ecosystems forest and savanna can be found in Figure 9, along with the corresponding results of the ATSR-scaled MOZART inventory [Schultz, 2002]. For the GWEM CO emissions in both runs, a global maximum for both savanna and forest in June is observed. In Figure 9a the GWEM-1.20 forest emissions clearly dominate the scenario. Another smaller maximum of $\mathrm{CO}$ emissions is found in the Northern Hemispheric winter (in December), resulting from numerous savanna fires in northern Africa. The scaled MOZART emissions show a quite different seasonality compared to GWEM. The graphs for forest and savanna $\mathrm{CO}$ emissions are qualitatively very similar, which is caused by the scaling methodology [Schultz, 2002]. Peaks are observed in August and October for both biomes

Table 6. Geographical Regions From Which Individual GWEM-1.0 Results are Obtained $^{\mathrm{a}}$

\begin{tabular}{|c|c|c|c|}
\hline $\begin{array}{l}\text { Region } \\
\text { Number }\end{array}$ & Name of Region & Abbreviation & Countries or Geographical Latitude/Longitude Describing Region \\
\hline 1 & North America & N-AM & Canada, United States of America \\
\hline 2 & Central America & C-AM & $\begin{array}{l}\text { Costa Rica, El Salvador, Grenada, Guatemala, Honduras, Mexico, } \\
\text { Nicaragua, Panama, all Caribbean islands }\end{array}$ \\
\hline 3 & South America & S-AM & $\begin{array}{l}\text { Argentina, Bolivia, Brazil, Chile, Colombia, Ecuador, French Guiana, } \\
\text { Guyana, Paraguay, Peru, Suriname, Uruguay, Venezuela }\end{array}$ \\
\hline 4 & northern Africa & $\mathrm{N}-\mathrm{AF}$ & all African countries north of the equator \\
\hline 5 & southern Africa & S-AF & all African countries south of the equator \\
\hline 6 & Western Europe & W-EU & $\begin{array}{l}\text { Austria, Belgium, Denmark, Finland, France, Germany, Greece, Ireland, } \\
\text { Italy, Netherlands, Norway, Portugal, Spain, Sweden, Switzerland, United Kingdom }\end{array}$ \\
\hline 7 & Eastern Europe & E-EU & $\begin{array}{l}\text { Belarus, Bosnia-Herzegovina, Bulgaria, Croatia, Czech Republic, Hungary, } \\
\text { Kazakhstan until } 60^{\circ} \text { east, Macedonia, Poland, Romania, Russian Federation } \\
\text { until } 60^{\circ} \text { east, Slovakia, Slovenia, Ukraine, Yugoslavia }\end{array}$ \\
\hline 8 & north/central Asia & NC-AS & Russian Federation from $60^{\circ}$ east, Kazakhstan, Mongolia \\
\hline 9 & Near East & N-EA & $\begin{array}{l}\text { Afghanistan, Armenia, Cyprus, Georgia, Iran, Iraq, Israel, Jordan, Kyrgyzstan, } \\
\text { Lebanon, Pakistan, Saudi Arabia, Syrian Arab Republic, Turkey, Uzbekistan, Yemen }\end{array}$ \\
\hline 10 & east Asia & E-AS & Japan, North Korea, South Korea \\
\hline 11 & southern Asia & S-AS & $\begin{array}{l}\text { Bangladesh, Bhutan, Brunei, Cambodia, China, India, Indonesia, Hongkong, } \\
\text { Malaysia, Myanmar, Nepal, Taiwan, Thailand, Vietnam }\end{array}$ \\
\hline 12 & Oceania & OCE & Australia, New Zealand, Polynesia \\
\hline
\end{tabular}

${ }^{\mathrm{a}}$ Only the main contributing countries are listed. 

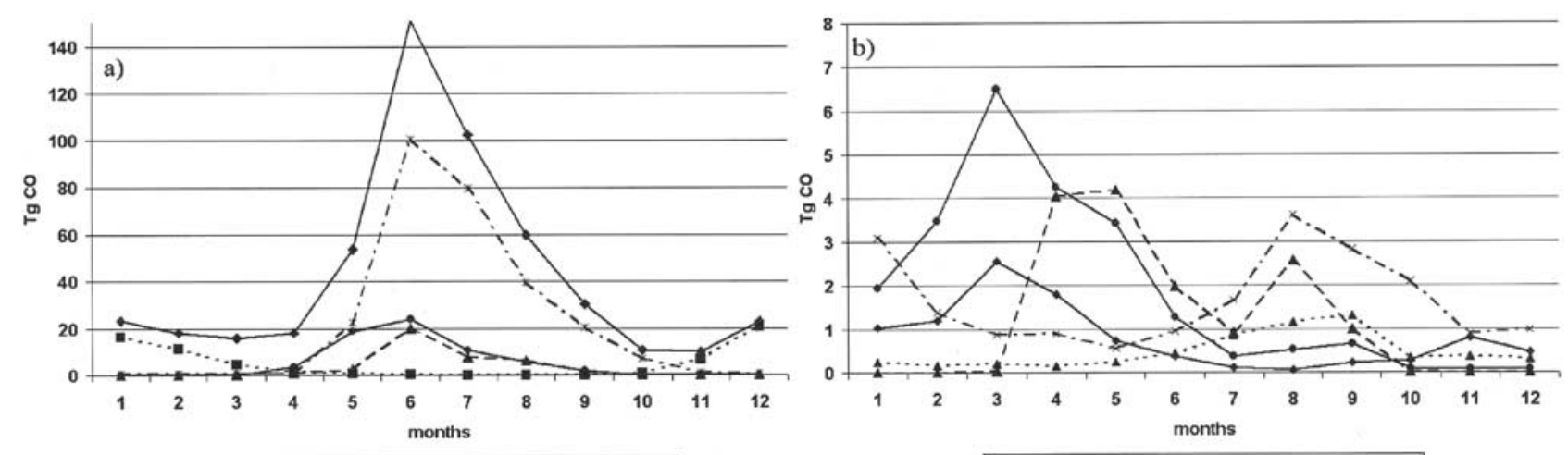

$\cdot \mathrm{N}-\mathrm{AM} \rightarrow \mathrm{NC}-\mathrm{AS} \cdot \mathrm{a} \cdot \mathrm{N}-\mathrm{AF} \rightarrow$ - global $-x-\mathrm{S}-\mathrm{AF}$
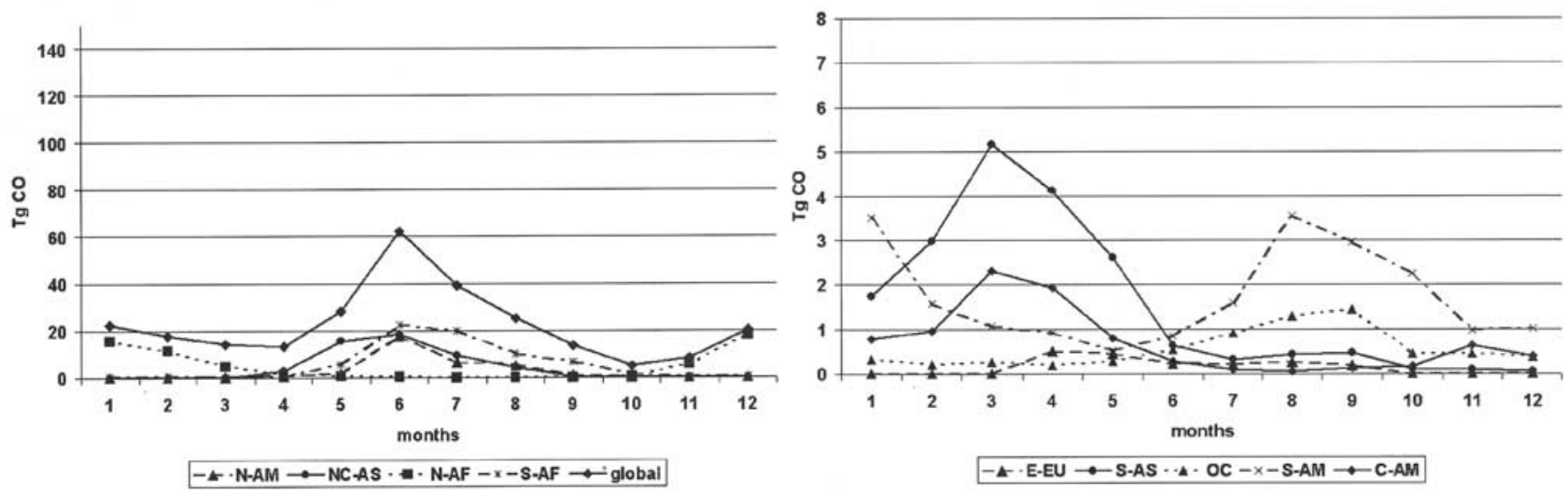

Figure 7. (a) CO monthly emissions from wildland fires in 2000 computed by GWEM-1.20 (IGBP) (above) and GWEM-1.21 (below) for the regional main contributors North America (N-AM), north central Asia (NC-AS), northern Africa (N-AF), and southern Africa (S-AF). (b) CO monthly emissions from wildland fires in 2000 computed by GWEM-1.20 (IGBP) (above) and GWEM-1.21 (below) for the regional contributors Central America (C-AM), Eastern Europe (E-EU), southern Asia (S-AS), Oceania (OC), and South America (S-AM).

and a very smooth increase of the savanna emissions can be seen for January, followed by another smaller one in April for forests. A further discussion of the seasonality in GWEM is given in section 5.

\section{Discussion}

[44] The results of GWEM are largely dependent on the validity and limitations of the input data used, which should therefore also be a topic of discussion. An attempt was made to gather data on sources and emissions of the year 2000 for terms of comparison. Data for other years than 2000 must be used with caution because of the extremely high variability of fire emission related data. Nevertheless, for many times it is the only available reference to obtain a first appraisal of results. The area burnt and the available fuel load as principal input sources are regarded as well as the emissions of different species for different regions.

\subsection{Discussion of Input Data}

\subsubsection{Area Burnt}

[45] Table 10 lists the regional totals of the GLOBSCAR area burnt in $\mathrm{km}^{2}$ as used in GWEM-1.20 and GWEM-1.21. Since area burnt pixels with the pure agricultural vegetation class 12 and nonvegetated classes (13 and 15-17) are removed, the presented numbers differ owing to the use of the two different land cover schemes, IGBP-DIS and MODIS. The most obvious differences of area burnt between GWEM-1.20 and GWEM-1.21 are found for Eastern Europe. The MODIS map in GWEM-1.21 contains many pixels associated with the vegetation class 12 "croplands," which are removed from the analysis in this study. In case of GWEM-1.20 (IGBP), these pixels are assigned to other vegetation classes $(6,8,9,11$, and 14$)$, which are part of the ecosystems savanna and grasslands and woody savannas (see Table 1) and are counted as burnt areas. Similar explanations hold for other regions as well.

[46] Table 10 yields an interesting comparison for northern Africa (N-AF) and north central Asia (NC-AS): the GLOBSCAR area burnt in N-AF is more than 5 times higher than in NC-AS. Nevertheless, the resulting emissions are of the same order in both regions (Tables 7 and 8). The explanation is given by the much lower fuel loads in the predominant savanna ecosystem in N-AF compared to NCAS. Fires in N-AF are more frequent but emit much less than the boreal forest fire dominated NC-AS region.

[47] Many areas in Canada are falsely detected as burnt in GLOBSCAR owing to an error in the algorithm (meanwhile revised for forthcoming products). Low albedo regions are mistaken for burnt areas. Other products, such as GBA2000 and the ATSR active fire counts, show considerably less activity in Canada throughout the year 2000. Fires 

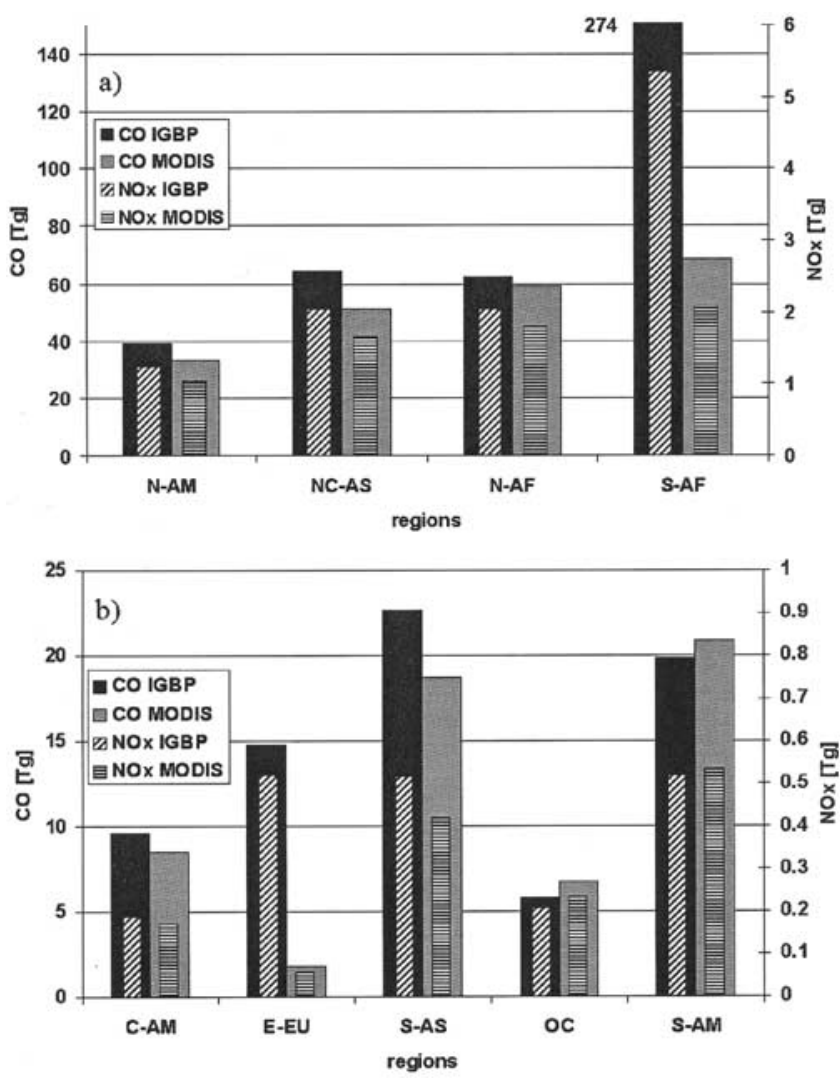

Figure 8. $\mathrm{CO}$ and $\mathrm{NO}_{x}$ regional totals from wildland fires in 2000 computed by GWEM-1.20 (IGBP) and GWEM-1.21 (MODIS) for (a) North America, north central Asia, northern Africa, and southern Africa and (b) Central America, Eastern Europe, southern Asia, Oceania, and South America.

considerably smaller than $1 \mathrm{~km}^{2}$ cannot be detected by the GLOBSCAR algorithm. This has a big impact in regions where small fires dominate. This is the case for deforestation fires in tropical rain forest, e.g., Brazil and Indonesia, but also in small savanna fires in southern Africa (S-AF) [Hély et al., 2003a]. Therefore it is expected that GWEM emissions are under-estimated in these regions. However, there is another effect associated with this: the GLOBSCAR numbers for S-AF in Table 11 show a lower area burnt for GWEM-1.20 compared to the MODIS based GWEM-1.21 run, while the emissions in Table 8 clearly state a different trend. GWEM-1.20 provides about four times higher $\mathrm{CO}$ emissions than GWEM-1.21 $\left(\mathrm{NO}_{x}\right.$, factor of 2.6 (Table 9); $\mathrm{CO}_{2}$, factor of 2.8 (not shown)). The explanation is that the IGBP land cover map allocates tropical forest vegetation classes to many of the GLOBSCAR pixels in S-AF, while the MODIS map associates wooded savanna ecosystems with these pixels, which have a considerably lower fuel load and thus much lower emissions. In numbers, GWEM-1.20 yields $38 \%$ tropical forest pixels and $35 \%$ wooded savanna pixels out of a total of $0.5 \times 10^{6}$ in S-AF, while GWEM-1.21 equivalent numbers are 3 and $61 \%$, respectively, out of a total of $0.58 \times 10^{6}$ pixels.

[48] With regard to the extent of present deforestation and because of improved methodology and data sets, the MODIS

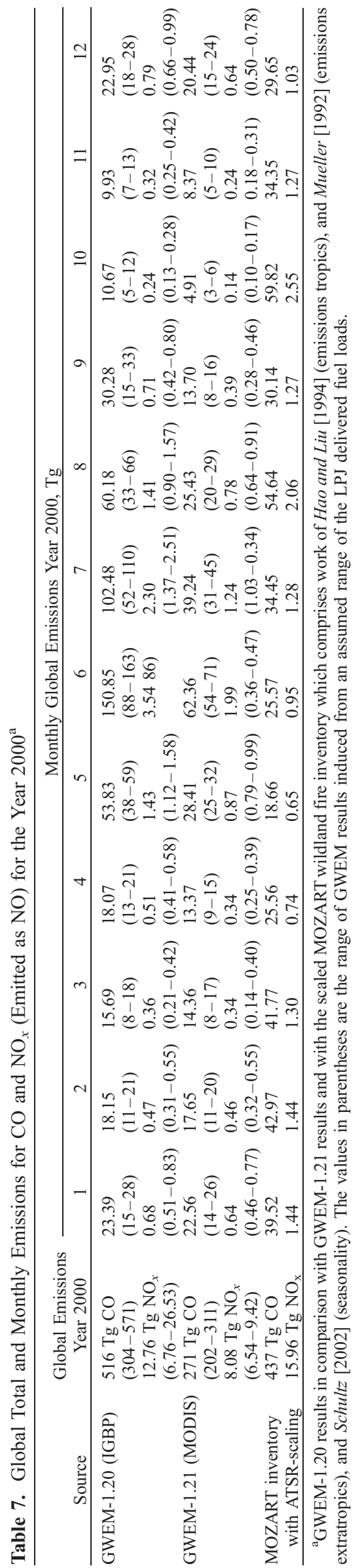


Table 8. Regional Wildland Fire Emissions for CO in $\operatorname{Tg}\left(1 \mathrm{Tg}=10^{12} \mathrm{~g}\right)$ for the Year $2000^{\mathrm{a}}$

\begin{tabular}{|c|c|c|c|}
\hline \multirow[b]{2}{*}{ Region } & \multicolumn{3}{|c|}{$\mathrm{CO}$} \\
\hline & $\begin{array}{c}\text { GWEM-1.20 (IGBP), } \\
\text { Tg }\end{array}$ & $\begin{array}{c}\text { GWEM-1.21 (MODIS), } \\
\text { Tg }\end{array}$ & $\begin{array}{l}\text { MOZART Inventory With } \\
\text { ATSR Scaling, Tg } \\
\end{array}$ \\
\hline North America & $39.20(37.23-42.81)$ & $33.32(31.61-36.45)$ & 28.80 \\
\hline Central America & $9.63(4.79-10.22)$ & $8.51(4.23-9.18)$ & 8.72 \\
\hline South America & $19.83(11.53-22.30$ & $20.85(11.75-23.32)$ & 98.63 \\
\hline Northern Africa & $62.60(47.13-76.64)$ & $59.28(40.95-70.94)$ & 135.62 \\
\hline Southern Africa & $274.45(110.05-294.43)$ & $68.67(46.88-82.00)$ & 92.27 \\
\hline Western Europe & $0.72(0.64-0.87)$ & $0.49(0.45-0.58)$ & 5.54 \\
\hline Eastern Europe & $14.78(13.76-16.76)$ & $1.83(1.74-2.00)$ & 7.52 \\
\hline North central Asia & $64.24(60.84-70.93)$ & $51.12(48.87-55.51)$ & 10.71 \\
\hline Near East & $0.05(1.28-1.52)$ & $0.73(0.68-0.81)$ & 1.98 \\
\hline East Asia & $0.01(0.01-0.02)$ & $0.02(0.01-0.02)$ & 0.02 \\
\hline Southern Asia & $22.65(11.86-25.84)$ & $18.70(9.63-21.25)$ & 24.83 \\
\hline Oceania & $5.83(4.70-7.62)$ & $6.74(5.30-8.67)$ & 23.45 \\
\hline
\end{tabular}

land cover map, and thus GWEM-1.21, is believed to be closer to the truth. Another new vegetation map (GLC2000) [Bartholomé et al., 2002] shows only minor differences to the MODIS data set, at least as far as this study is concerned.

[49] Area burnt data have been compared to other published values in individual regions. S-AF is the region with most available data for comparisons, owing to campaigns such as the SAFARI 2000 initiative [Swap et al., 2002]. An overview of published burnt area estimates is listed in Table 11. The JRC's satellite product GBA-2000 [Grégoire et al., 2003; Tansey et al., 2004] represents the only comparable global data set for the year 2000. The GLOBSCAR product used in this work yields an area burnt of $0.58 \times 10^{6} \mathrm{~km}^{2}$ for S-AF (GWEM-1.21) in the year 2000. According to the GLOBSCAR validation report [Simon, 2002], the area burnt calculated for GLOBSCAR is generally lower than for GBA-2000. GBA-2000 incorporates an area burnt spread-region algorithm, which connects area burnt records belonging to the same fire scar. Owing to the spatial resolution of $1 \mathrm{~km}^{2}$ of these satellite products, they always provide lower values of area burnt than other approaches that are able to monitor fires with smaller extensions. Furthermore, the year 2000 was a year with moderate fire occurrences.
[50] A regional study in Western Europe (W-EU) for the year 2000 has been performed by P. M. Barbosa et al. (Forest fire emissions in southern Europe: First estimates from 2000, submitted to Journal of Geophysical Research, 2003, hereinafter referred to as Barbosa et al., submitted manuscript, 2003) for the main Mediterranean countries (Portugal, Spain, France, Italy, and Greece). Burnt area estimates from this work are derived from the Indian Remote Sensing Satellite (IRS), which detects burnt scars bigger than $0.5 \mathrm{~km}^{2}$. The total amount of area burnt for 2000 was $3867 \mathrm{~km}^{2}$. GLOBSCAR detected a slightly lesser area burnt at $3390 \mathrm{~km}^{2}$ (GWEM-1.21) for the whole of W-EU, which includes the UK, Scandinavia, and Germany.

[51] The seasonality in GWEM arises solely from the monthly area burnt provided by GLOBSCAR. The basic seasonal behavior as described in section 4 agrees with the generally known patterns of regional burning seasons. However, one of the two maxima occurs about 2 months earlier than in other global wildland fire emission inventories [e.g., Galanter et al., 2000; Duncan et al., 2003; Schultz, 2002].

[52] A qualitative comparison of the monthly number of area burnt records from GLOBSCAR with ATSR active fire

Table 9. Regional Total Emissions for $\mathrm{NO}_{x}$ (as NO) in $\mathrm{Tg}\left(1 \mathrm{Tg}=10^{12} \mathrm{~g}\right)$ for the Year $2000^{\mathrm{a}}$

\begin{tabular}{lccc}
\hline & & NO $_{x}$ & \\
\cline { 2 - 4 } \multicolumn{1}{c}{ Region } & GWEM-1.20, Tg & GWEM-1.21, Tg & $\begin{array}{c}\text { MOZART Inventory With } \\
\text { ATSR Scaling, Tg }\end{array}$ \\
\hline North America & $1.250(1.195-1.365)$ & $1.050(0.997-1.143)$ & 0.792 \\
Central America & $0.188(0.100-0.203)$ & $0.172(0.093-0.188)$ & 0.141 \\
South America & $0.520(0.353-0.601)$ & $0.534(0.352-0.614)$ & 3.333 \\
Northern Africa & $2.050(1.643-2.557)$ & $1.800(1.371-2.204)$ & 5.073 \\
Southern Africa & $5.360(2.347-5.834)$ & $2.090(1.578-2.555)$ & 4.326 \\
Western Europe & $0.024(0.022-0.029)$ & $0.017(0.016-0.020)$ & 0.155 \\
Eastern Europe & $0.522(0.487-0.591)$ & $0.061(0.058-0.067)$ & 0.211 \\
North central Asia & $2.050(1.945-2.256)$ & $1.670(1.596-1.803)$ & 0.300 \\
Near East & $0.046(0.044-0.052)$ & $0.026(0.024-0.029)$ & 0.066 \\
East Asia & $0.000(0.006$ & 0.0006 \\
Southern Asia & $0.517(0.316-0.590)$ & $0.000(0.000-0.001)$ & 0.5270 \\
Oceania & $0.208(0.171-0.274)$ & $0.420(0.250-0.478)$ & 1.080 \\
\hline
\end{tabular}

${ }^{\mathrm{a}}$ GWEM-1.20 and GWEM-1.21 results in comparison with the scaled MOZART wildland fire inventory which comprises work of Hao and Liu [1994] (emissions tropics), Mueller [1992] (emissions extratropics), with ATSR scaling by Schultz [2002] (seasonality). The values in parentheses are the range of GWEM results. 

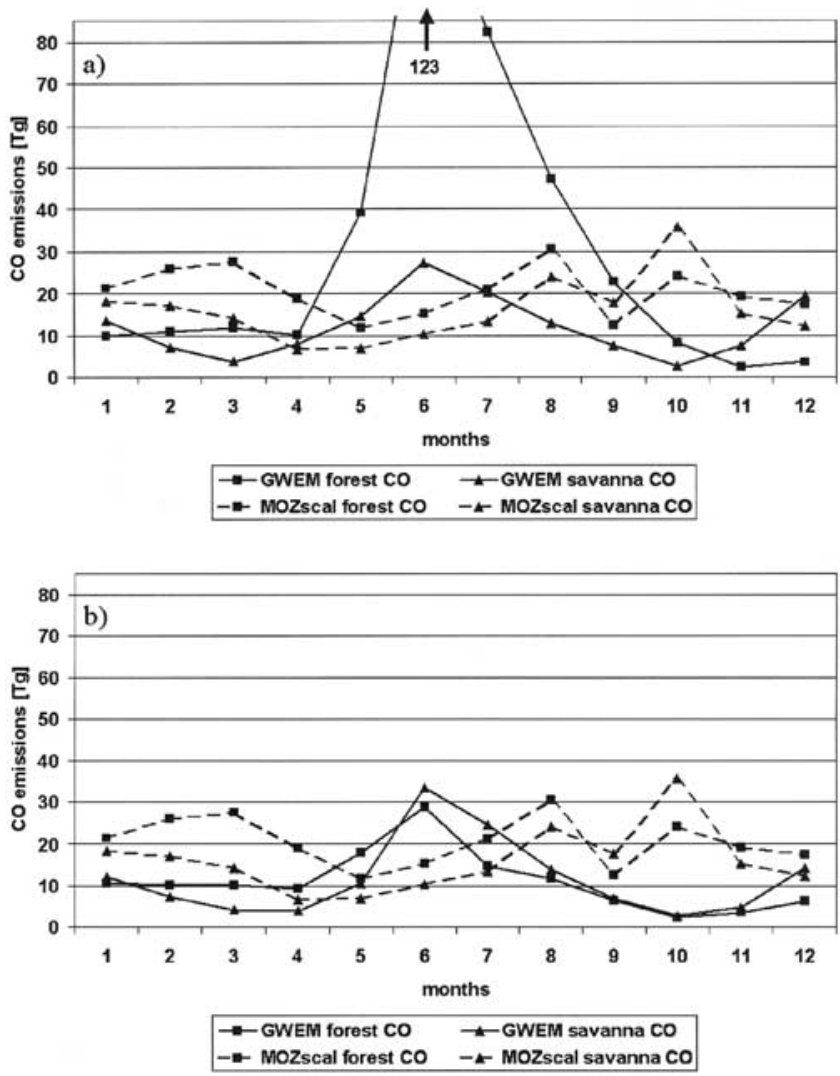

Figure 9. Forest and savanna emissions of (a) GWEM-1.20 (IGBP) and (b) GWEM-1.21 (MODIS) together with the ATSR scaled MOZART inventory forest and savanna emissions for carbon monoxide in the year 2000 .

counts (Figure 10) shows that the maxima of GLOBSCAR occur in June and December, while for the ATSR fire counts the maxima are observed in August and December. Also, AVHRR data of fire counts (World Fire Web, JRC, Ispra, published in the work of Dwyer et al. [2000]) from the $1992 / 1993$ period show distinct maxima in these two months. The differences can be reconciled in light of the different quantities observed.

[53] Active fire counts do not reveal information about the associated burnt scar size. Therefore the different

Table 10. Regional Totals of the GLOBSCAR Area Burnt in $\mathrm{km}^{2}$ for GWEM-1.20 and GWEM-1.21

\begin{tabular}{lcc}
\hline & $\begin{array}{c}\text { GLOBSCAR } \\
\text { Area Burnt in } \\
\text { GWEM-1.20, km }\end{array}$ & $\begin{array}{c}\text { GLOBSCAR } \\
\text { Area Burnt in } \\
\text { GWEM-1.21, km }\end{array}$ \\
\hline North America & 77,215 & 70,371 \\
Central America & 20,409 & 20,471 \\
South America & 123,391 & 126,767 \\
Northern Africa & 583,158 & 603,864 \\
Southern Africa & 504,684 & 577,083 \\
Western Europe & 3722 & 3390 \\
Eastern Europe & 52,519 & 9631 \\
North central Asia & 108,764 & 87,981 \\
Near East & 9642 & 8123 \\
East Asia & 86 & 88 \\
Southern Asia & 40,596 & 35,981 \\
Oceania & 176,892 & 177,603 \\
\hline
\end{tabular}

Table 11. Area Burnt Estimates for Southern Africa in $10^{6} \mathrm{~km}^{2}$ for Different Years Available in the Literature and From GLOBSCAR

\begin{tabular}{|c|c|}
\hline & Southern Africa \\
\hline GLOBSCAR (GWEM-1.20) & 0.51 \\
\hline GLOBSCAR (GWEM-1.21) ${ }^{\mathrm{a}}$ & 0.58 \\
\hline GBA- $2000^{\mathrm{a}}$ & 0.72 \\
\hline van der Werf et al. [2003] $]^{\mathrm{b}}$ & 1.16 \\
\hline Barbosa et al. [1999] ${ }^{c}$ & 1.54 \\
\hline Scholes et al. $[1996]^{\mathrm{d}}$ & 1.68 \\
\hline
\end{tabular}

${ }^{\mathrm{a} E s t i m a t e}$ for the year 2000.

${ }^{\mathrm{b}}$ Annual estimate from $1998-2001$.

cAnnual mean value of two different scenarios for 1981-1991.

${ }^{\mathrm{d}}$ Satellite data derived estimate for the year 1989 .

maxima in Figure 10 may imply that the maximum of the ATSR active fire counts in August results from many small fires with small burnt scars, while the GLOBSCAR peak in June takes place because of a reduced number of larger fires. This is reinforced by the fact that according to the GLOBSCAR Products Qualification Report [Simon, 2002] the GBA-2000 product is in qualitative agreement with GLOBSCAR results concerning regional seasonalities.

[54] For the S-AF region the global maximum is also observed in June resulting from wet miombo fires in the northern countries (e.g., Democratic Republic of Congo). Together with the anomalous numbers in North America for June (false detections in Canada), this explains the unusual global peak, while the lack of a distinct peak later in the season may be a superposition of omission effects in other regions such as S-AF's southern countries, where many typical small one-day fires in the burning season are undetected by satellites owing to their small extension. These assertions need to be verified in a careful multisensor data analysis.

[55] Apart from the seasonality, there is a general underestimation of burnt areas in GLOBSCAR resulting from (1) the spatial resolution of the data set, which cannot reliably detect small fires, (2) cloud coverage which renders a representative assessment of burnt areas impossible in regions like northern Brazil and Indonesia, and (3) understory peat fires mainly in Russia and Indonesia, which are not detected owing to a lack of change in the surface albedo after a fire and low-temperature properties. Apparently, other satellite area burnt products on the same resolution, such as GBA-2000, reveal the similar omission problems and are therefore probably not a real alternative.

[56] In summary, the findings on the GLOBSCAR product were the following: there is a good performance, e.g., in northern Africa, Europe, and northwestern Australia. Regions with insufficient performance have been identified as: Canada, USA, Zimbabwe, Brazil, and Indonesia. More investigation is needed to further improve and evaluate the remote sensing detection of burnt areas. For further discussion of the GLOBSCAR product, see Simon [2002] and Simon et al. [2004].

\subsubsection{Available Fuel Load}

[57] The output from the LPJ vegetation model available for this study is broken down in four different carbon pools: litter, leaf, wood, and fine roots. From these carbon pools the AFLs for the different ecosystems were derived as described in section 3.2 


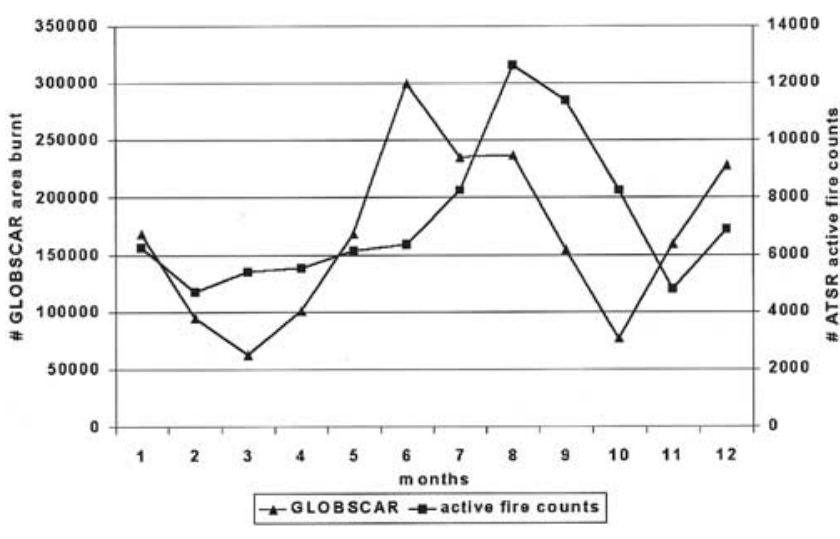

Figure 10. Number of $1 \times 1 \mathrm{~km}^{2}$ area burnt detections by GLOBSCAR versus number of detected ATSR active fire counts in the year 2000 .

[58] An attempt was made to evaluate the AFLs listed in Table 2 and the numbers in Table 3 , which are needed to derive available fuel load from the LPJ biomass density. The latter is essential because most burning efficiencies in literature refer to the available fuel load and not to the total biomass load. However, literature values for these percentages are, if existent, highly diverse and difficult to compare. Often, it remains unclear if the values denote (1) the total biomass load, (2) the aboveground biomass density, (3) a tree mortality rate, which denotes only the percentage of the trees that die as an effect of the fire, or (4) the available fuel load, which is the part of the vegetation that can potentially burn in a natural wildland fire. Sometimes even the percentages are directly merged with the burning efficiency numbers, and a separation is therefore impossible without further knowledge. Nevertheless, some information could be gathered: in the work of Thonicke et al. [2001], a fire resistance (FIR) for the woody plant functional types (PFTs) in different ecosystems is used in the LPJ fire module. The FIR stands for the survival of the woody PFTs (trees) one year after a fire. The disturbance of the vegetation is therefore $1-$ FIR. The FIR percentages are given for living biomass $(\mathrm{K}$. Thonicke, personal communication, 2003). Assuming that the percentage of dry matter of this living biomass is between 50 and $70 \%$ [Andreae and Merlet, 2001], this delivers the following disturbances for the LPJ carbon pools wood and leaf: up to $25 \%$ of trees in a savanna type ecosystem and $25-62 \%$ of trees in all forest type ecosystems die within one year after a fire. According to Table 3 in this study, the applied percentages are mostly near the lower end of the range and at times even below that. This is consistent with the GWEM approach that considers only direct fire combustion effects on the vegetation rather than long-term ecological effects, which need to take into account postfire mortality of trees.

[59] Reid et al. (manuscript in preparation, 2003) compiled a variety of literature values for AFL for different ecosystems. A comparison of these numbers to the corresponding AFL values used in GWEM is presented in Table 2. The GWEM AFLs generally match the wide range of the literature values, except for boreal forest. The literature numbers for boreal forest are far lower than for other forest types and compared to the GWEM boreal forest. Some of the discrepancy may be a result of the incoherent terminology (see above). In addition, the literature values may be biased because only trees above a certain diameter are counted in forestry statistics. This implies that, in particular, the most fire susceptible parts of the vegetation are not taken into account in these studies. Generally, the original AFL in GWEM would be systematically underestimated for forest ecosystems and exceed the published values for savannas ecosystems in mixed grid boxes, which contain both types of ecosystems. This discrepancy arises from the coarser $0.5 \times 0.5$ resolution of the LPJ model compared to the $1 \mathrm{~km}^{2}$ resolution of the GLOBSCAR product. In the mixed grid boxes the amount of wood provided by LPJ is given for the whole grid box, which is either too elevated for a pure savanna or grassland fire of $1 \mathrm{~km}^{2}$ extension, or too low, if the burnt pixel is located in a forest. This systematic error has been addressed by scaling functions that depend on the ratio of wood versus total biomass load per LPJ grid box. The AFL in mixed grid boxes is decreased with increasing wood content for savanna fires and vice versa. We hope that this artifact can be avoided by including individual PFTs of LPJ in future GWEM versions.

[60] Another factor affecting the AFL data may be the fire history: primary tropical rain forest, for example, has a very different susceptibility to fire and burning characteristics compared to secondary rain forest which has already burnt before. This is due to the stepwise conversion into savanna or pastureland during each consecutive fire event [Goldammer, 1999]. Finally, in some savanna regions, AFL may have to be reduced due to grazing cattle.

\subsubsection{Emission Factors}

[61] The global average emission factors compiled by Andreae and Merlet [2001] provide a useful reference for global emission estimates. A lot of effort has been placed into the determination of emission factors during the past decade. Thus they are currently not the main source of uncertainties in global wildland fire emission modeling. Nevertheless, there is still room for further improvement in terms of the number of ecosystems (currently three categories for wildland fires) and for some species for which less data is available. In addition, there have been discussions whether to distinguish between emission factors from smoldering and flaming fires. Each fire has a flaming and a smoldering phase. Depending on the fuel type and its moisture content, the smoldering combustion phase may be prolonged. Measurements taken from particular fires in these two phases differ considerably. On the global scale, however, it is not necessary to consider this distinction and average values should suffice [Andreae and Merlet, 2001].

[62] The trace gases $\mathrm{CO}_{2}, \mathrm{CO}$, and $\mathrm{CH}_{4}$ have the most reliable emission factors owing to many verified published measurements, whereas trustworthy quality aerosol emission estimates from biomass burning are more difficult to obtain. Still, there seems to exist good and consistent information on the latter as well, taken from slightly aged smoke plumes (approximately $1-2$ hours). For further details, see Andreae and Merlet [2001].

\subsection{Discussion of Emissions}

[63] Table 7 lists the monthly and total emissions of $\mathrm{CO}$ and $\mathrm{NO}_{x}$ obtained in the two GWEM versions as well as the 
Table 12. Area Burnt in $\mathrm{km}^{2}$, Mean Available Fuel Load in $\mathrm{g} / \mathrm{m}^{2}$ and Emissions of CO in Tg for August and September 2000 in Subequatorial Africa ${ }^{\mathrm{a}}$

\begin{tabular}{|c|c|c|c|c|c|c|}
\hline \multirow[b]{2}{*}{ Data } & \multicolumn{2}{|c|}{ GWEM-1.20 } & \multicolumn{2}{|c|}{ GWEM-1.21 } & \multicolumn{2}{|c|}{ Hély et al. [2003a, 2003b] } \\
\hline & August 2000 & September 2000 & August 2000 & September 2000 & August 2000 & September 2000 \\
\hline $\begin{array}{l}\text { Area burnt, } \mathrm{km}^{2} \\
\text { AFL, }{ }^{\mathrm{d}} \mathrm{g} / \mathrm{m}^{2}\end{array}$ & $76,201^{b}$ & $\begin{array}{l}38,671^{\mathrm{b}} \\
2800(306-25,614)\end{array}$ & $76,201^{b}$ & $\begin{array}{l}38,671^{\mathrm{b}} \\
1085(310-10,049)\end{array}$ & $162,328^{\mathrm{c}}$ & $\begin{array}{l}95,962^{\mathrm{c}} \\
351(3-1311)\end{array}$ \\
\hline $\mathrm{CO}, \mathrm{Tg}$ & 39.68 & 20.54 & 10.20 & 6.59 & 2.89 & 1.72 \\
\hline
\end{tabular}

${ }^{\mathrm{a}} \mathrm{GWEM}$ results in comparison with data from Hély et al. [2003b].

${ }^{\mathrm{b}}$ Area burnt data from GLOBSCAR, ESA/ESRIN.

${ }^{\mathrm{c}}$ Area burnt data from GBA-2000, JRC.

${ }^{\mathrm{d}}$ Mean value of this area and range.

values from the ATSR-scaled MOZART inventory of Schultz [2002]. The total numbers in GWEM-1.21 are considerably lower with $271 \mathrm{Tg} \mathrm{CO}$ (and $8.08 \mathrm{Tg} \mathrm{\textrm {NO } _ { x }}$ compared to $437 \mathrm{Tg} \mathrm{CO}$ ) and $15.96 \mathrm{Tg} \mathrm{NO}_{x}$ of the scaled MOZART inventory. The emission inventory by Galanter et al. [2000] yields $554 \mathrm{Tg} \mathrm{CO}$ and $14.12 \mathrm{Tg} \mathrm{NO}_{x}$ for annual savanna and forest fire emissions and is thus also much higher than the GWEM emissions. Generally, GWEM arrives at lower monthly values compared to the ATSR inventory, as might be expected from the global totals. However, this relation is inverted for the months May and June, where GWEM clearly exceeds the scaled MOZART results. This feature mainly results from the shifted seasonality in southern Africa and the false detections in Canada, which have their maximum in June. In contrast, emissions for the month of October are much lower than in the MOZART inventory.

[64] Tables 8 and 9 list the regional emission totals (for the definition of the regions, see Figure 6) for $\mathrm{CO}$ and $\mathrm{NO}_{x}$, respectively. There is reasonable agreement between GWEM and the scaled MOZART inventory for Central America, southern Asia, eastern Asia, and North America. For North America, one needs to bear in mind though that this is due to a cancellation of errors: As discussed in section 5.1, the GLOBSCAR area burnt product induces a considerable commission error in Canada for some months. This is balanced by omission of fires in the USA (GLOBSCAR validation report) [Arino and Plummer, 2001]. As discussed above, in Africa and South America, many small fires remain undetected in GLOBSCAR, and consequently the emission estimates are rather low. Large discrepancies between the inventories are also observed in Oceania and north central Asia. In Australia the GLOBSCAR algorithm misses many savanna fires, and in the interior of the continent the daytime ATSR data have a gap (similar to north central Asia but much smaller).

[65] For north central Asia GWEMs, CO emissions are more than 4.5 times higher than the scaled MOZART values, which is a result of the elevated fuel loads in GWEM. Considering the data gap discussed in section 2.2, the real emissions in this region may still be somewhat higher. The ATSR nighttime fire counts, which we used to fill in the gap, are known to miss many lowtemperature fires, so that the fire density in this region remains lower than elsewhere.

[66] On the regional scale, there are more studies available for comparison: Southern Africa is a region with extensive data available from diverse measurement campaigns, e.g., SAFARI-92 [Andreae et al., 1996], SAFARI2000 [Swap et al., 2002], and TRACE-A [Fishman et al., 1996]. However, for the year 2000, there is only one published study by Hély et al. [2003b] so far, who have CO emissions for August and September 2000 (Table 12). The estimated GLOBSCAR area burnt for these two months in southern Africa is more than $40 \%$ below the estimates of Hély et al. [2003b]. GLOBSCAR under-detects a lot of subpixel fires in some countries of southern Africa such as Zimbabwe and Mozambique [see Simon, 2002]. However, the average AFL used in GWEM is more than a factor of 3 higher than in the work of Hély et al. [2003b]. These discrepancies highlight the importance of a correct land cover classification: In GWEM (1.21), more of the fires occur in wooded savanna, or even in tropical forest, while the Hély et al. [2003b] study apparently attributes most fires to savannas. In addition, there are likely differences in the emission factors used.

[67] For the whole African continent, Barbosa et al. (submitted manuscript, 2003) have estimated an emitted amount of 40-151 Tg CO. GWEM-1.21 best guess result for carbon monoxide emissions in Africa is $128 \mathrm{Tg} \mathrm{CO}$ (range: 88-153). van der Werf et al. [2003], Scholes et al. [1996], and Barbosa et al. [1999] have calculated an average yearly carbon amount of 516, 80, and $205 \mathrm{Tg} \mathrm{C}$ (mean value of two scenarios), respectively, released in subequatorial Africa. In comparison, GWEM yields 473 (349-576) $\mathrm{Tg} \mathrm{C}$ in this region. These studies were each made for different years, and a quantitative intercomparison with the year 2000 is therefore questionable. The area burnt values in the different studies (discussed in section in 5.1) are not linearly related to the emissions. This leads to the conclusion that the available fuel load must also differ substantially between the various estimates.

[68] Barbosa et al. (submitted manuscript, 2003) calculated wildland fire emissions from the five Mediterranean countries in Europe and estimated that $0.46 \mathrm{Tg} \mathrm{CO}$ and $0.024 \mathrm{Tg} \mathrm{NO}{ }_{x}$ were emitted. GWEM results yield $0.49 \mathrm{Tg}$ $\mathrm{CO}(0.45-0.58)$ and $0.017 \mathrm{Tg} \mathrm{NO}_{x}(0.016-0.020)$, for all of Western Europe, respectively. Since the five Mediterranean countries in the work of Barbosa et al. (submitted manuscript, 2003) are the main contributors for Europe, a comparison of these numbers appears reasonable. The results agree surprisingly well for a region where mainly small fire sizes are expected. This small number in comparison to the well-matching emission estimates is again due to the available fuel load data. The LPJ-DGVM used in GWEM has few anthropogenic processes included and therefore assumes high forest coverage for Europe, which leads to a higher carbon combustion when burning.

[69] It should be noted that agricultural fires have explicitly been excluded from GWEM in order to avoid an 
overlap with agricultural waste fire emissions in chemistry transport modeling. To illustrate the potential impact of agricultural fires (i.e., the subset of fires seen from space), we have performed an additional run based on the MODIS land cover map, which includes the IGBP vegetation class 12. The available fuel load has been assumed to be similar to that of wooded savanna and emission factors were taken from Andreae and Merlet [2001]. The inclusion of fires in pixels marked as agricultural land leads to the additional global release of $16 \mathrm{Tg} \mathrm{CO}$ and $0.59 \mathrm{Tg} \mathrm{NO}_{x}$.

\section{Uncertainties}

[70] The uncertainties of the GWEM input data have been reported for the burning efficiency (Table 5) and the emission factors (Table 4). The uncertainty for the latter varies considerably for different species. While emission factors of species such as $\mathrm{CO}_{2}, \mathrm{CO}$, and $\mathrm{CH}_{4}$, for example, are quite well known owing to the broad availability of measurements in literature, others rely on one documented measurement only [see Andreae and Merlet, 2001). Typically, the uncertainty of emission factors is in the order of $20-30 \%$. For the burning efficiency, uncertainty ranges between $12 \%$ in savanna and grasslands and $20 \%$ in the forests.

[71] A first simple approach to uncertainty assessment in terms of the AFL input was integrated in GWEM by attributing a minimum-maximum range to the AFL data. The uncertainty assessment for the burnt area from satellites, such as GLOBSCAR, is a difficult task. Several questions arise which are difficult to answer on a quantitative basis: How much of a $1 \mathrm{~km}^{2}$ area burnt record is really burnt? How much of the areas burnt remain unseen owing to almost permanent cloud coverage, especially during the burning season? How much of dark soil is mistaken for burnt area? How many small and patchy areas burnt are ignored by the satellite? How many peat fires are omitted owing to their low temperature and invisibility in terms of reflectance?

[72] The validation of a global product such as GWEM can only be performed in a multitier approach: Comparisons and uncertainty estimates must be made both for the individual input data sets as well as for the final product. Likewise, scales from local (a few GLOBSCAR pixels) to global must be considered. A first assessment of the impact of the emission factors uncertainty on the model results is underway following the approach of van Aardenne [2002].

\section{Conclusions}

[73] The presented versions of the Global Wildland Fire Emission Model (GWEM) provide estimates of annual fire emissions of chemical tracers and particles for the year 2000 based on (1) GLOBSCAR, a satellite observed burnt area; (2) model derived available fuel loads; and (3) two different land cover classification schemes. Globally, the resulting emissions are significantly lower than previous estimates. A detailed inspection of the individual factors contributing to the emission estimates indicates that there is a significant under-estimation in the GLOBSCAR burnt areas, in particular for regions with many small fires. Thus applications in global modeling must consider additional data for calculating emissions of the small but intense deforestation fires in South America and small savanna fires in Africa. Future satellitederived fire products should be based on multiple sensors and combine burnt area information with hot spot detection in order to increase the completeness of the product.

[74] The largest uncertainties in the presented GWEM versions stem from the burnt area product and from the available fuel load map. The AFL is currently being refined to contain carbon pools for individual plant functional types in forthcoming GWEM versions. Also, the fire-seasonal variation of emission factors and burning efficiencies should be related to varying fuel moisture conditions. A study by Hoffa et al. [1999] has shown that the emission factors and burning efficiencies change considerably from the beginning to the end of the burning season. In order to reconcile the existing differences between current estimates of global fire emissions, a detailed comparison of these inventories including a critical appraisal of their underlying input data should be performed.

[75] In the end it should be noted that the focus of this study has been an evaluation of the GLOBSCAR area burnt product. Newer GWEM versions exist that are based on a more elaborated combination of data sets. The model is continuously improved. All updated inventories are available upon request to gwem@dkrz.de.

[76] Acknowledgments. We especially thank the organizers of this special issue, E. Kasischke and J. Penner. We would like to acknowledge J. G. Goldammer and M. O. Andreae for helpful discussions and the latter also for providing unpublished data on emission factors. We thank H. Eva and S. Fritz from JRC, S. Plummer from ESA, and K. Thonicke from PIK for many more helpful discussions and data. We thank J. Feichter and A. Heil for the internal review and S. Kinne for a linguistic polish of this manuscript. This manuscript has benefitted substantially from the detailed comments of the two anonymous reviewers. This work was supported by the German Max Planck Society.

\section{References}

Andreae, M. O., and P. Merlet (2001), Emission of trace gases and aerosols from biomass burning, Global Biogeochem. Cycles, 15(4), 955-966.

Andreae, M. O., J. Fishman, and J. Lindesay (1996), The Southern Tropical Atlantic Experiment (STARE): Transport and Atmospheric Chemistry Near the Equator-Atlantic (TRACE A) and Southern African Fire-Atmosphere Research Initiative (SAFARI): An introduction, J. Geophys. Res., 101(D19), 23,519-23,520.

Andreae, M. O., et al. (2001), Transport of biomass burning smoke to the upper troposphere by deep convection in the equatorial region, Geophys. Res. Lett., 28(6), 951-954.

Arino, O. and S. Plummer (2001), The along-track scanning radiometer World Fire Atlas detection of night-time fire activity, Validation report, IGBP-DIS Working Pap. 23, Int. Geosph. Biosph. Progr., Stockholm.

Arino, O., I. Piccolini, and J. M. Rosaz (2000), Development and testing of algorithms for a global burnt area product from ERS ATSR-2, paper presented at IGARSS Symposium, Inst. of Electr. and Electron. Eng., Honolulu, Hawaii.

Arino, O., M. Simon, I. Piccolini, and J. M. Rosaz (2001), The ERS-2 ATSR-2 World Fire Atlas and the ERS-2 ATSR-2 World Burnt Surface Atlas projects, paper presented at 8th ISPRS Conference on Physical Measurement and Signatures in Remote Sensing, Int. Soc. for Photogramm. and Remote Sens., Aussois, 8-12 Jan.

Barbosa, P. M., D. Stroppiana, and J.-M. Grégoire (1999), An Assessment of vegetation fire in Africa (1981-1991), Burned areas, burned biomass, and atmospheric emissions, Global Biogeochem. Cycles, 13(4), 933950 .

Bartholomé, E., A. S. Belward, F. Achard, S. Bartalev, C. Carmona Moreno, H. Eva, S. Fritz, J.-M. Grégoire, P. Mayaux, and H.-J. Stibig (2002), Global land cover mapping for the year 2000-Project status November 2002, Rep. EUR 20524, Joint Res. Cent. of the Eur. Commiss., Brussels.

Cooke, W. F., and J. J. N. Wilson (1996), A global black carbon aerosol model, J. Geophys. Res., 101, 19,395-19,409.

Duncan, B. N., R. V. Martin, A. C. Staudt, R. Yevich, and J. A. Logan (2003), Interannual and seasonal variability of biomass burning emissions 
constrained by satellite observations, J. Geophys. Res., 108(D2), 4100 , doi:10.1029/2002JD002378.

Dwyer, E., S. Pinnock, and J.-M. Grégoire (2000), Global spatial and temporal distribution of vegetation fire as determined from satellite observations, Int. J. Remote Sens., 21(6-7), 1289-1302.

Eva, H., and E. F. Lambin (1998a), Burnt area mapping in central Africa using ATSR data, Int. J. Remote Sens., 19(18), 3473-3497.

Eva, H., and E. F. Lambin (1998b), Remote sensing of biomass burning in tropical regions: Sampling issues and multisensor approach, Remote Sens. Environ., 64, 292-315.

FIRESCAN Science Team (1996), Fire in ecosystems of boreal Eurasia: The Bor Forest Island Fire Experiment Fire Research Campaign AsiaNorth (FIRESCAN), in Biomass Burning and Global Change, vol. 1, edited by J. S. Levine, pp. 848-873, MIT Press, Cambridge, Mass.

Fishman, J., J. M. Hoell Jr., R. D. Bendura, R. J. McNeal, and V. W. J. H Kirchhoff (1996), NASA GTE TRACE A Experiment (SeptemberOctober 1992): Overview, J. Geophys. Res., 101(D19), 23,865-23,879.

Friedl, M. A., et al. (2002), Global land cover mapping from MODIS Algorithms and early results, Int. J. Remote Sens., 83, 287-302.

Galanter, M., H. Levy II, and G. R. Carmichael (2000), Impacts of biomass burning on tropospheric $\mathrm{CO}, \mathrm{NO}_{\mathrm{x}}$, and $\mathrm{O}_{3}, J$. Geophys. Res., 105(D5), $6633-6653$

Generoso, S., F. M. Bréon, Y. Balkanski, O. Boucher, and M. Schulz (2003), Improving the seasonal cycle and interannual variations of biomass burning aerosol sources, Atmos. Chem. Phys., 3, 1211-1222.

Goldammer, J. G. (1999), Forests on fire, Science, 284, 1782-1783

Govaerts, Y. M., J. M. Pereira, B. Pinty, and B. Mota (2002), Impact of fires on surface albedo dynamics over the African continent, J. Geophys. Res., 107(D22), 4629, doi:10.1029/2002JD002388

Grégoire, J.-M., K. Tansey, and J. M. N. Silva (2003), The GBA-2000 initiative: Developing a global burned area database from SPOT-VEGETATION imagery, Int. J. Remote Sens., 24(6), 1369-1376.

Guild, L. S., J. B. Kauffman, L. J. Ellingson, D. L. Cummings, E. A Castro, R. E. Babbitt, and D. E. Ward (1998), Dynamics associated with total aboveground biomass, $\mathrm{C}$, nutrient pools, and biomass burning of primary forest and pasture in Rondonia, Brazil, during SCAR-B, J. Geophys. Res., 103, 32,091-32,100.

Hao, W. M., and M.-H. Liu (1994), Spatial and temporal distribution of tropical biomass burning, Global Biogeochem. Cycles, 8(4), 495-504.

Hao, W. M., M. H. Liu, and P. J. Crutzen (1990), Estimates of annual and regional releases of $\mathrm{CO}_{2}$ and other trace gases to the atmosphere from fire in the tropics, based on FAO statistics for the period 1975-1980, in Fire in the Tropical Biota, edited by J. G. Goldammer, pp. 440-462, Springer-Verlag, New York

Hély, C., P. R. Dowty, S. Alleaume, K. K. Caylor, S. Korontzi, R. J. Swap, H. H. Shugart, and C. O. Justice (2003a), Regional fuel load for two climatically contrasting years in southern Africa, J. Geophys. Res., 108(D13), 8475, doi:10.1029/2002JD002341.

Hély, C., K. Caylor, S. Alleaume, R. J. Swap, and H. H. Shugart (2003b), Release of gaseous and particulate carbonaceous compounds from biomass burning during the SAFARI 2000 dry season field campaign, J. Geophys. Res., 108(D13), 8470, doi:10.1029/2002JD002482.

Hobbs, P. V., and L. F. Radke (1969), Cloud condensation nuclei from a simulated forest fire, Science, 163, 279-280.

Hobbs, P. V., J. S. Reid, J. A. Herring, J. D. Nance, R. E. Weiss, J. L. Ross, D. A. Hegg, R. D. Ottmar, and C. Liousse (1996), Particle and trace-gas measurements in smoke from prescribed burns of forest products in the Pacific Northwest, in Biomass Burning and Global Change, vol. 1, edited by J. S. Levine, pp. 697-715, MIT Press, Cambridge, Mass.

Hoffa, E. A., D. E. Ward, W. M. Hao, R. A. Susott, and R. H. Wakimoto (1999), Seasonality of carbon emissions from biomass burning in a Zambian savanna, J. Geophys. Res., 104(D11), 13,841-13,853.

Horowitz, L. W., et al. (2003), A global simulation of tropospheric ozone and related tracers: Description and evaluation of MOZART, version 2, J. Geophys. Res., 108(D24), 4784, doi:10.1029/2002JD002853.

Intergovernmental Panel on Climate Change (IPCC) (2001), Climate Change 2001: The Scientific Basis, Contribution of Working Group I to the Third Assessment Report of the Intergovernmental Panel on Climate Change, edited by J. T. Houghton et al., Cambridge Univ. Press, New York.

Kasischke, E. S., and L. P. Bruhwiler (2002), Emissions of carbon dioxide, carbon monoxide, and methane from boreal forest fires in 1998, J. Geophys. Res., 107, 8146, doi:10.1029/2001JD000461. [printed 108(D1), 2003]

Kauffman, J. B., D. L. Cummings, D. E. Ward, and R. Babbitt (1995), Fire in the Brazilian Amazon: Biomass, nutrient pools, and losses in slashed primary forest, Oecologia, 104, 397-408.

Kauffman, J. B., D. L. Cummings, and D. E. Ward (1998), Fire in the Brazilian Amazon, 2: Biomass, nutrient pools, and losses in cattle pastures, Oecologia, 113, 415-427.
Lavoué, D. (2000), Transport vers la région arctique de l'aerosol carbone emis par les feux de biomasse des régions boréale et temperée, Ph.D. thesis, Univ. Paris VII, UFR de Chim., Paris.

Lavoué, D., C. Liousse, H. Cachier, B. J. Stocks, and J. G. Goldammer (2000), Modeling of carbonaceous particles emitted by boreal and temperate wildland fires at northern latitudes, J. Geophys. Res., 105(D22), 26,871-26,890.

Liousse, C., J. E. Penner, C. Chuang, J. J. Walton, and H. Eddleman (1996), A global three-dimensional model study of carbonaceous aerosols, J. Geophys. Res., 101(D14), 19,411-19,432.

Lobert, J. M., W. C. Keene, J. A. Logan, and R. Yevich (1999), Global chlorine emissions from biomass burning: Reactive chlorine emissions inventory, J. Geophys. Res., 104(D7), 8373-8389.

Loveland, T. R., and A. S. Belward (1997), The IGBP-DIS global 1-km land cover data set. Discover: First results, Int. J. Remote Sens., 65(9), $1021-1031$

Loveland, T. R., B. C. Reed, J. F. Brown, D. O. Ohlen, J. Zhu, L. Yang, and J. W. Merchant (2000), Development of a global land cover characteristics database and IGBP Discover from 1-km AVHRR data, Int. J. Remote Sens., 21(6-7), 1303-1330

Mueller, J. F. (1992), Geographical distribution and seasonal variation of surface emissions and deposition velocities of atmospheric trace gases, J. Geophys. Res., 97, 3787-3804.

Pereira, J. M. C., B. Pereira, P. Barbosa, D. Stroppiana, M. J. P. Vasconcelos, and J. M. Grégoire (1999), Satellite monitoring of fire in the EXPRESSO study area during the 1996 dry season experiment: Active fires, burnt area, and atmospheric emissions, J. Geophys. Res., 104, 30,701-30,712.

Scholes, R. J., J. Kendall, and C. O. Justice (1996), The quantity of biomass burned in southern Africa, J. Geophys. Res., 101, 23,667-23,676.

Schultz, M. G. (2002), On the use of ATSR fire count data to estimate the seasonal and interannual variability of vegetation fire emissions, Atmos. Chem. Phys., 2, 387-395.

Seiler, W., and P. J. Crutzen (1980), Estimates of gross and net fluxes of carbon between the biosphere and the atmosphere from biomass burning, Clim. Change, 2, 207-247.

Shea, R. W., B. W. Shea, J. B. Kauffman, D. E. Ward, C. I. Haskins, and M. C. Scholes (1996), Fuel biomass and combustion factors associated with fires in savanna ecosystems of South Africa and Zambia, J. Geophys. Res., 101, 23,551-23,568.

Simon, M. (2002), GLOBSCAR products qualification report, Tech. Note, Eur. Space Ag., Paris

Simon, M., S. Plummer, F. Fierens, J. J. Hoelzemann, and O. Arino (2004) Burnt area detection at global scale using ATSR-2: The GLOBSCAR products and their qualification, J. Geophys. Res., 109, doi:10.1029/ 2003JD003622, in press.

Sitch, S., et al. (2003), Evaluation of ecosystem dynamics, plant geography and terrestrial carbon cycling in the LPJ dynamic global vegetation model, Global Change Biol., 9, 161-185.

Stocks, B. J., B. W. van Wilgen, W. S. W. Trollope, D. J. McRae, J. A. Mason, F. Weirich, and A. L. F. Potgieter (1996), Fuels and fire behavior dynamics on large-scale savanna fires in Kruger National Park, South Africa, J. Geophys. Res., 101, 23,541-23,550

Stohl, A., S. Eckhardt, C. Forster, P. James, and N. Spichtinger (2002), On the pathways and timescales of intercontinental air pollution transport, J. Geophys. Res., 107(D23), 4684, doi:10.1029/2001JD001396.

Swap, R. J., H. J. Annegarn, and L. Otter (2002), Southern African Regional Science Initiative (SAFARI 2000): Summary of science plan, S. Afr. J. Sci., 98, 119-124

Tansey, K., et al. (2004), Vegetation burning in the year 2000: Global burned area estimates from SPOT VEGETATION data, J. Geophys. Res., 109, doi:10.1029/2003JD003598, in press.

Thonicke, K., S. Venevsky, S. Sitch, and W. Cramer (2001), The role of fire disturbance for global vegetation dynamics: Coupling fire into a dynamic global vegetation model, Global Ecol. Biogeogr., 10, 661-677.

Trollope, W. S. W., and L. A. Trollope (1996), SAFARI-92 characterization of biomass and fire behavior in the small experimental burns in the Kruger National Park, J. Geophys. Res., 101, 23,531-23,539.

Twomey, S. (1977), The Influence of pollution on the shortwave albedo of clouds, J. Atmos. Sci., 34, 1149-1152.

Twomey, S., and J. Warner (1967), Comparison of Measurements of cloud droplets and cloud nuclei, J. Atmos. Sci., 24, 702-703.

van Aardenne, J. A. (2002), Uncertainties in emission inventories, Ph.D. thesis, Wageningen Univ., Wageningen, Netherlands.

van der Werf, G. R., J. T. Randerson, G. J. Collatz, and L. Giglio (2003) Carbon emissions from fires in tropical and subtropical ecosystems, Global Chang. Biol., 9, 547-562.

Ward, D. E., and W. M. Hao (1992), Air toxic emissions from burning of biomass globally-preliminary estimates, paper presented at 85th Annual Meeting and Exhibition, Air and Waste Manage. Assoc., Pittsburgh, $\mathrm{Pa}$. 
Ward, D. E., R. A. Susott, J. B. Kauffman, R. E. Babbitt, D. L. Cummings, B. Dias, B. N. Holben, Y. J. Kaufman, R. A. Rasmussen, and A. W. Setzer (1992), Smoke and fire characteristics for Cerrado and deforestation burns in Brazil: BASE-B experiment, J. Geophys. Res., 97(D13), $14,601-14,619$

Ward, D. E., W. M. Hao, R. A. Susott, R. E. Babbitt, R. W. Shea, J. B. Kauffman, and C. O. Justice (1996), Effect of fuel composition on combustion efficiency and emission factors for African savanna ecosystems, J. Geophys. Res., 101, 23,569-23,576.

Wotawa, G., P. C. Novelli, M. Trainer, and C. Granier (2001), Inter-annual variability of summertime $\mathrm{CO}$ concentrations in the Northern Hemisphere explained by boreal forest fires in North America and Russia, Geophys. Res. Lett., 28(24), 4575-4578.

G. P. Brasseur, C. Granier, J. J. Hoelzemann, and M. G. Schultz, Max Planck Institute for Meteorology, Bundesstr. 55, D-20146 Hamburg, Germany. (hoelzemann@dkrz.de)

M. Simon, European Space Agency (ESA), ESRIN, via Galileo Galilei, Frascati I-00044, Italy. 